\title{
WestVirginiaUniversity
}

THE RESEARCH REPOSITORY @ WVU

Graduate Theses, Dissertations, and Problem Reports

2019

\section{Low Power Voltage Reference Cells for Sensing Applications}

\author{
Kody Ray Tucker \\ Wesy Virginia University, krtucker@mix.wvu.edu
}

Follow this and additional works at: https://researchrepository.wvu.edu/etd

Part of the Electrical and Electronics Commons

\section{Recommended Citation}

Tucker, Kody Ray, "Low Power Voltage Reference Cells for Sensing Applications" (2019). Graduate Theses, Dissertations, and Problem Reports. 7403.

https://researchrepository.wvu.edu/etd/7403

This Problem/Project Report is protected by copyright and/or related rights. It has been brought to you by the The Research Repository @WVU with permission from the rights-holder(s). You are free to use this Problem/Project Report in any way that is permitted by the copyright and related rights legislation that applies to your use. For other uses you must obtain permission from the rights-holder(s) directly, unless additional rights are indicated by a Creative Commons license in the record and/ or on the work itself. This Problem/Project Report has been accepted for inclusion in WVU Graduate Theses, Dissertations, and Problem Reports collection by an authorized administrator of The Research Repository @ WVU. For more information, please contact researchrepository@mail.wvu.edu. 


\title{
Low Power Voltage Reference Cells for Sensing Applications
}

\author{
Kody R. Tucker \\ Problem Report submitted to the \\ Benjamin M. Statler College of Engineering and Mineral Resources \\ at West Virginia University \\ in partial fulfillment of the requirements \\ for the degree of \\ Master of Science \\ in \\ Engineering \\ David W. Graham, Ph.D., Chair \\ Jeremy Dawson, Ph.D. \\ Roy Nutter, Ph.D. \\ Lane Department of Computer Science and Electrical Engineering
Morgantown, West Virginia
2019 \\ Keywords: Analog, Layout, Low Power, Output Voltage $\left(V_{O U T}\right)$, \\ Simulation, Reference Voltage $\left(V_{R E F}\right)$, Temperature Coefficent(TC)
}

Copyright 2019 Kody R. Tucker 


\begin{abstract}
Low Power Voltage Reference Cells for Sensing Applications
\end{abstract}

Kody R. Tucker

Two low-power voltage reference cells for a system on-chip design are presented in this report. Both cells utilize a combination of standard transistors to produce an output voltage near 1 volt. Choosing the appropriate design procedures can aid in minimizing the temperature coefficient (TC) of the output reference voltage coming out of the cell. One circuit, covered first, is currently being fabricated on a standard $0.5 \mu \mathrm{m}$ chip complementary metal oxide semiconductor (CMOS) process, while the other is still in the designing stage. The first one has a $\mathrm{TC}$ of $86 \mathrm{ppm} /{ }^{\circ} \mathrm{C}$ with a reference voltage of $1.10 \mathrm{~V}$ while consuming $1.25 \mu \mathrm{W}$ of power by simulation. The second voltage reference cell is aimed for a lower TC, and power consumption approximately $37 \mathrm{ppm} /{ }^{\circ} \mathrm{C}$ and $2 \mathrm{nW}$ in simulation. Additionally, ideas to improve the circuits will be explored, and the layout of the first cell will be presented in this paper. 


\section{Acknowledgments}

To my committee chair and advisor, Dr. Graham, as well as my fellow CESLAB members for their advice and help along this journey. In addition, I would like to thank my mother, father, and little sister for their support. 


\section{Contents}

Abstract ii

Acknowledgments $\quad$ iii

List of Figures $\quad$ V

List of Tables vi vi

1 Introduction 1

2 Reference Cell with above 1V Output 5

2.1 Background ..................... 5

2.2 Design Procedure and Results . . . . . . . . . . . . . . 11

2.3 Layout of Voltage Reference Cell . . . . . . . . . . . . . . 14

2.4 Results of first reference cell simulation . . . . . . . . . . 22

3 Reference Cell with below 1V Output 26

3.1 Background . . . . . . . . . . . . . . 26

3.2 Design Procedure . . . . . . . . . . . . . . . . . . 31

3.3 Results and Comparison . . . . . . . . . . . . . 34

4 Conclusion \& Future Work 38

4.1 Conclusion . . . . . . . . . . . . . . . . . . . 38

4.2 Future Work . . . . . . . . . . . . . . . . . . . . . . 39

$\begin{array}{ll}\text { References } & 41\end{array}$ 


\section{List of Figures}

2.1 Diagram of Voltage Reference Cell . . . . . . . . . . . . . 6

2.2 Navidi's original voltage reference cell . . . . . . . . . . 9

2.3 (a)Navidi's Original Cell, (b) New Cell . . . . . . . . . . . 11

$2.4 V_{D D}$ sweep effects on $V_{O U T} \ldots \ldots \ldots \ldots \ldots$

2.5 Temperature sweep effects on $V_{\text {OUT }} \ldots \ldots \ldots \ldots$

2.6 Circuit with MUXes and Pins . . . . . . . . . . . . . 15

2.7 Pad Connections . . . . . . . . . . . . . . 16

2.8 Chip Connections . . . . . . . . . . . . . . . . . . . . . . . 17

2.9 Layout of PMOS . . . . . . . . . . . . . . . . 18

2.10 Layout of $\mathrm{M} 7 \ldots \ldots \ldots$

2.11 Layout of NMOS . . . . . . . . . . . . . . . . 19

2.12 Layout of NMOS(zoomed-in) . . . . . . . . . . . . . . . . . . . . . 19

2.13 Layout of Capacitor $C_{s}(3.1 \mathrm{pF}) \ldots \ldots . \ldots 20$

2.14 Layout of Resistors . . . . . . . . . . . . . . . . . . . . . 20

2.15 Layout of a MUX . . . . . . . . . . . . . . . 21

2.16 Parasitics caused by overlapping of metals . . . . . . . 22

2.17 Output Voltage of $V_{R E F} \ldots \ldots \ldots \ldots . \ldots . \ldots . \ldots 23$

2.18 Graphing of TC . . . . . . . . . . . . . . 24

3.1 Ueno-based Circuit . . . . . . . . . . . . . . . . 28

3.2 Differential Op Amp . . . . . . . . . . . . . . . . . 28

$3.30 .5 \mu \mathrm{m}$ Output Voltage . . . . . . . . . . . . . . . . . . . 34

3.4 Temperature Sweep Graph . . . . . . . . . . . . . 35 


\section{List of Tables}

2.1 Circuit \#1 transistor widths \& lengths . . . . . . . . . . . 12

2.2 Comparing circuit \#1 work with other works . . . . . . . . 24

3.1 Circuit \#2 transistor widths and lengths . . . . . . . . . 34

3.2 Comparing circuit \#2 work with other works . . . . . . . . 35

4.1 Comparing both Circuits . . . . . . . . . . . . . . . . 39 


\section{Chapter 1}

\section{Introduction}

In electronics, a voltage reference is a device that produces a constant output voltage despite factors such as power supply variations, temperature changes, and the current load on the device. In modern times, they are used in power supplies, both ADC and DAC converters, and other control systems. Depending on their specific design, these circuits vary extensively in performance, and in many cases, these circuits are constant enough that measurements involving stability and precisions, like temperature coefficients, are measured in parts per million. These circuits can provide a potential for long periods of time whether it be minutes, hours, days, or years. Additionally, they are used in comparator and detection circuits. Other information can be found in [1].

An example utilized in integrated circuits would be the bandgap voltage reference circuit. This is a temperature-independent circuit that has an output voltage of approximately 1.25 volts; the theoretical $1.22 \mathrm{eV}$ bandgap of Silicon is close to this output voltage[2]. They can produce current that is proportional to absolute temperature (PTAT) in a resistor and voltage that is complementary to absolute temperature (CTAT) by using analog circuits to add a single multiple of difference of voltage between 2 bipolar junctions biased at contrasting current densities to the diode voltage as detailed in [1] and [3]. A circuit with an output voltage close to but below 
the bandgap value will be explored in Chapter 2.

A widely known bandgap circuit is the one created by Paul Brokaw which manages two internal voltage sources. One has a positive temperature coefficient, and the other has a negative temperature coefficient. This circuit employs negative feedback due to the operation of an operational amplifier to impose current constantly through the two bipolar transistors as covered in [3].

In earlier designs, many circuits required voltage regulators to bias a low current load while maintaining a reasonable level of voltage precision and accuracy. A common method was to use a Zener diode normally in parallel with the output voltage with both connected to a resistor which is connected to a power supply. This configuration creates a voltage rail; however, issues can occur with this method as a low resistance is required for a small reverse-bias current. Along with smaller tolerances, these are prone to have larger power losses. A voltage reference circuit can maintain the voltage with a smaller amount of current, a larger tolerance in resistance and keep power losses minimal with additional information in [4].

As newer technology materializes allowing for lower supply voltages, a goal of recent designs such as Brokaw's has been to produce a low reference voltage using a low supply voltage. Having an output voltage sufficiently larger than 1 volt causes a tradeoff between having a low temperature coefficient (TC) and low power consumption. In other words, a lower TC requires a greater power consumption. There a lot of circuits with recent development that have produced reference voltages less than or equal to one volt. An example would be the sub-bandgap circuit created by Oscar E. Mattia which produced a TC range of 11 to $83 \mathrm{ppm} /{ }^{\circ} \mathrm{C}$ in the 0.13 $\mu \mathrm{m}$ process and an output voltage of $570 \mathrm{mV}$. Sweeping between a 0.9-1.2 $\mathrm{V}$ power supply $V_{D D}$, the power consumption for the minimum TC value would be $35 \mathrm{nW}$ and $5 \mathrm{nW}$ for the maximum TC. In this circuit, he used some MOSFETS and a Bipolar Junction Transistor. These transistors composed three parts of the circuit: a self-cascode PTAT generator, a BJT 
bias circuit, and a VE divider. Mattia mentions more information in [5].

Another practice of voltage reference is in the development of ultra-low power LSIs designed to operate in the subthreshold region of MOSFETs. In the subthreshold region, the gate-source voltage of MOSFETs is lower than its threshold voltage. These LSIs are designed for power-monitoring LSI applications. Examples of these applications include portable mobile devices, implantable medical devices, and smart sensor networks[6]. These devices require a few microwatts or smaller of power as covered in [7] and [8].

Regarding LSIs, an example work of voltage references is the circuit designed by Ka Nang Leung. Designed in a $0.6 \mu \mathrm{m}$ process for low-dropout regulators, a temperature coefficient of $36.9 \mathrm{ppm} /{ }^{\circ} \mathrm{C}$ was achieved. Operated in the saturation region, the circuit required the weighted differences between the gate-source voltages $V_{g s}$ of both NMOS and PMOS. In addition to those types of transistors, resistors were included in the circuit to help achieve low bias current and an output of approximately $309 \mathrm{mV}$. This circuit had a power supply range of 1.4-3 volts and a maximum current supply of $9.7 \mu \mathrm{A}$ as Leung proves in [9]. Another example of a reference circuit involving LSI's is explored in chapter 3. For the idea of subthreshold operation, bandgap reference circuits with CMOS-based vertical bipolar transistors are quite common for LSI's as detailed in [9]. Unfortunately, when dealing with these types of circuits, high resistance requires a larger circuit area. As a result, it is not wise to use bandgap circuits. There have been modified voltage reference circuits for low-power LSIs such as Leung's, but a circuit like this can have various problems. For example, there are cases of large power dissipations and extremely sensitive output voltages when dealing with supply voltage and temperature variations with additional information according to Ken Ueno in [10].

The purpose of this paper involves two cells designed in the $0.5 \mu \mathrm{m}$ process. The first circuit is an improvement of the reference cell designed by Mir Muhammad Navidi that obtained a Temperature Coefficient of 
$42 \mathrm{ppm} /{ }^{\circ} \mathrm{C}$ and $1.11 \mu \mathrm{W}$ as covered in [11]. The improved circuit will be covered in Chapter 2. The second circuit is an adaptation of Ueno's circuit[10] with the main reason of this involves the taking a good excellent circuit from a technology node that I can't access and placing it into one that is accessible; this will be discussed in Chapter 3.

Voltage Reference cells are difficult to make as building a good one with a low TC is a great task when a low power is required. The goal of this research is to obtain a good TC and low amount of power for voltage reference cell design. To be specific, a TC less than $130 \mathrm{ppm} /{ }^{\circ} \mathrm{C}$ for a small range and a power consumption approximately 1.5 microwatt or less should be obtained as two circuits will be examined through simulation. An important circuit design here in the lab is the Reconfigurable Analog Mixed-Signal Platform originally designed by Brandon Rumberg and Dr. Graham for wireless sensing applications[12]. As the RAMP requires a constant voltage feeding into it at mid-rail known as half of the full power supply voltage, it would be nice if one of these two voltage references can serve this application by feeding its output into a voltage gain to bring its output voltage to mid-rail. 


\section{Chapter 2}

\section{Reference Cell with above 1V Output}

\subsection{Background}

In this chapter, a specific voltage reference cell is presented as it uses a combination of PMOS and NMOS standard thin-oxide transistors to produce a voltage above $1 \mathrm{~V}$. The purpose of the design is to minimize the temperature coefficient, represented as TC, of the output voltage. Currently at a foundry, this circuit is being fabricated in a standard $0.5 \mu \mathrm{m}$ CMOS process with additional MUXes added to the circuit. Individually, with a power consumption of $1.25 \mu \mathrm{W}$, the cell produces an output voltage of $1.1 \mathrm{~V}$ with a $\mathrm{TC}$ of $86 \mathrm{ppm} /{ }^{\circ} \mathrm{C}$ through simulation trials.

This voltage reference cell can simultaneously achieve a low TC over a large range of temperatures and low power consumption; to achieve this performance, there is a necessary condition requiring that the threshold voltages of standard (thin-oxide) transistors provide elevated voltages as well as the temperature characteristics for the circuit to have a low TC. The schematic diagram of the entire circuit is shown in Figure 2.1, and the circuit can be divided into 3 different sections: start-up circuit, PTAT current generator, and the temperature-independent voltage reference cell. 
The only difference in this new circuit is the reference cell. Due to this, most of the equations applicable to Navidi's original circuit can be applied to this new circuit as well as principles of operation as described in [11]. The operation of the start-up circuit acts like a switch which activates the PTAT generator, and this makes current $I_{R C}$ become a nonzero value with transistors $M_{4}$ and $M_{5}$ being temporarily "live", "on" in other words, to start the circuit. A current that is proportional to absolute temperature (PTAT) undergoes production by the current generator. The outer voltage reference portion of this circuit includes the transistor $M_{13}$, a resistor $R_{O U T}$, and a diode-connected transistor $M_{Z}$.

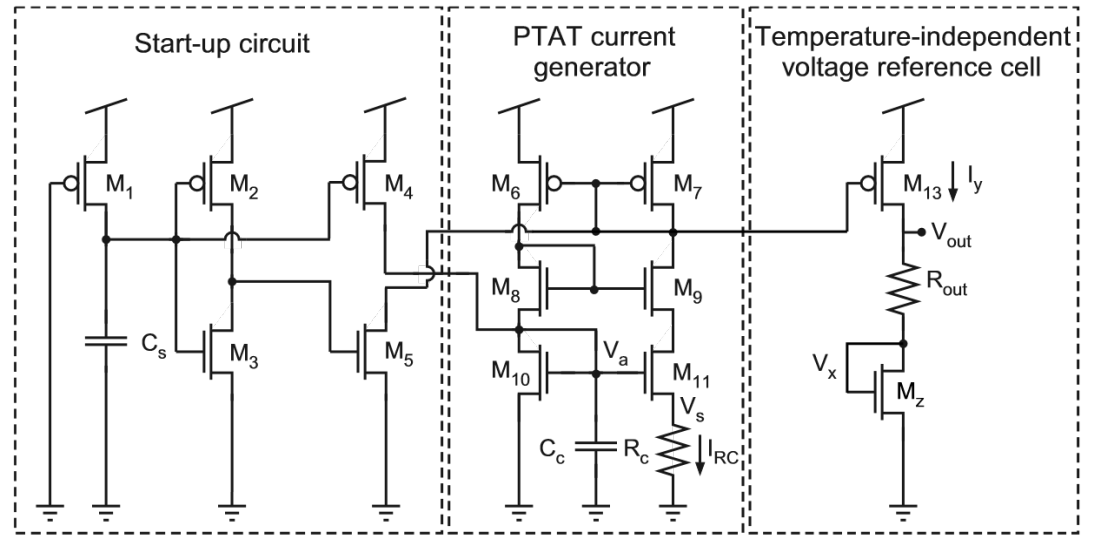

(a)

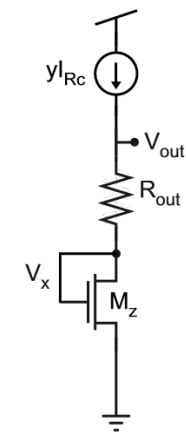

(b)

Figure 2.1: Diagram of Voltage Reference Cell

Displayed schematically in Figure 2.1, this cell is an improvement of Navidi's original cell for three reasons. The thick-oxide transistors that Navidi used in his cell as shown in figures 2.2 and 2.3(a), are becoming harder to purchase due to less of them being available. Also, thick oxides have different threshold voltages than the standard thin oxides. In some circumstances, these can cause issues in circuit performance. If both voltages increased or decreased in the same direction, the circuit should be fine, but if one threshold goes one way with the other going in the opposite direction, the circuit will not perform correctly. Another intention is the replacement of the reference cell portion with a simplified cell while keep- 
ing the start-up circuit and PTAT current generator of the original cell. Due to the simplification of the cell, changes in performance is expected, but with this new cell, the circuit can be used for a larger variety of applications while still being able to be examined mathematically using most of the equations Navidi used for his.

All transistors are standard MOSFETs. The voltage that is produced across the resistor $R_{C}$ is PTAT. This generated voltage allows current $I_{y}$ to be PTAT, and it can be expressed as displayed in (2.1). As the voltage is PTAT, this voltage can be calculated using (2.2). If (2.1) is used considering a claim that the transistor is biased in the sub-threshold region of operation, the voltage brought about on net $V_{x}$ is observed in (2.3). Net $V_{x}$ connects resistor $R_{O U T}$ to the drain and gate of transistor $M_{z}$. In these equations, $\mathrm{S}$ is the width/length ratio of a transistor.

$$
\begin{gathered}
I_{y}=U_{T}\left(\frac{1}{R_{C}}\right)\left(\frac{S_{13}}{S_{7}}\right) \ln \left(\frac{S_{11}}{S_{10}}\right) \\
V_{P T A T}=U_{T}\left(\frac{R_{O U T}}{R_{C}}\right)\left(\frac{S_{13}}{S_{7}}\right) \ln \left(\frac{S_{11}}{S_{10}}\right) \\
V_{x}=V_{T h}+\left(\frac{U_{T}}{\kappa}\right) \ln \left(\frac{I_{d}}{\left(S_{Z}\right)\left(I_{0}^{\prime}\right)}\right)
\end{gathered}
$$

According to Navidi, the threshold voltage term is considered to be complementary to absolute temperature(CTAT). In respect to this circuit, consider picking a large aspect ratio for transistor $M_{Z}$. By doing this, the output voltage can be calculated using (2.4) by placing threshold voltage being obtained by (2.5) into consideration. In (2.5), the term $\alpha V_{T h}$ is assumed to be negative. If the derivative of (2.4) is taken with respect to temperature to find the rate of change in voltage over the change in temperature, the circuit's TC can be found by the new equation labelled as (2.6). 


$$
\begin{gathered}
V_{\text {OUT }}=V_{T h}+\left(\frac{U_{T}}{\kappa}\right) \ln \left(\frac{I_{d}}{\left(S_{Z}\right)\left(I_{0}^{\prime}\right)}\right)+U_{T}\left(\frac{R_{O U T}}{R_{C}}\right)\left(\frac{S_{13}}{S_{7}}\right) \ln \left(\frac{S_{11}}{S_{10}}\right) \\
V_{T h}=\alpha V_{T h} T+V_{T h 0} \\
T C=\left|\frac{d V_{O U T}}{d T}\right|
\end{gathered}
$$

Theoretically, the temperature coefficient of the reference circuit's output voltage can be as minimal as zero ppm $/{ }^{\circ} \mathrm{C}$ by choosing the widths and lengths of $M_{7}, M_{13}, M_{10}, M_{11}, R_{O U T}, R_{C}$, and $M_{Z}$. Although zero TC is theoretically possible, this would not be obtained during trials. For this circuit to function well, a $\mathrm{TC}$ of $110 \mathrm{ppm} /{ }^{\circ} \mathrm{C}$ or less is appropriate. By setting the TC to zero, the term $\alpha V_{T h}$ can be found, and by inserting $\alpha V_{T h}$ in (2.4), the produced output voltage is approximately equivalent to the threshold voltage of a transistor as shown in (2.7).

$$
\begin{gathered}
V_{\text {OUT }}=V_{\text {Th0 }} \\
\left.I_{d}=I_{0}^{\prime} S \exp \left(\frac{\kappa\left(V_{g}-V_{T}\right)}{U_{T}}\right)\left(\exp \left(\frac{-V_{s}}{U_{T}}\right)-\exp \left(\frac{-V_{d}}{U_{T}}\right)\right)\right) \\
I_{0}^{\prime}=2 \eta \mu C_{O X} U_{T}^{2}
\end{gathered}
$$

As this circuit needs a low power consumption, the drain current of a subthreshold-operated MOSFET can be obtained by (2.8) by including (2.9). In these equations, $U_{T}$ is the thermal voltage with a value approximately $25.87 \mathrm{mV}, \kappa$ is the Boltzmann's constant, $\eta$ is the subthreshold slope, $\mu$ is the charge carrier mobility, and $C_{O X}$ represents the gate oxide capacitance per unit of area. The symbols: $V_{T}, V_{g}, V_{s}$, and $V_{d}$ represent the voltage at threshold, gate, source, and drain of a MOSFET, respectively. 
As shown in Figure 2.1, this PTAT current generator involves a current source and a current mirror. The voltage flowing to resistor $R_{C}$ is created by the difference in $V_{g s}$ values for $M_{10}$ and $M_{11}$. By the proper selection of the size of $R_{C}$ plus the width/length ratios for $M_{10}$ and $M_{11}$ while considering the latter to be greater than the former, all the transistors can be biased to operate in the subthreshold region of operation. Using (2.8) to solve for the currents in $M_{10}$ and $M_{11}$, the current generated by resistor $R_{C}$ can be calculated by (2.10) which proves that current increases as temperature increases. With a behavior similar to a low-pass filter, the capacitor $C_{C}$ stabilizes the gate voltage of $M_{10}$ and $M_{11}$ conveniently represented as voltage $V_{a}$ in Figure 2.1. To maintain a good TC for this reference cell, $R_{C}$ should be approximately one-sixth of the total resistance for $R_{O U T}$. It does not need to be exactly a ratio of 6.00 ; however, this ratio is quite handy when considering the creation of layout as explored in Section 2.3 .

$$
I_{R C}=\frac{V_{S}}{R_{C}}=U_{T}\left(\frac{1}{R_{C}}\right) \ln \left(\frac{S_{11}}{S_{10}}\right)
$$

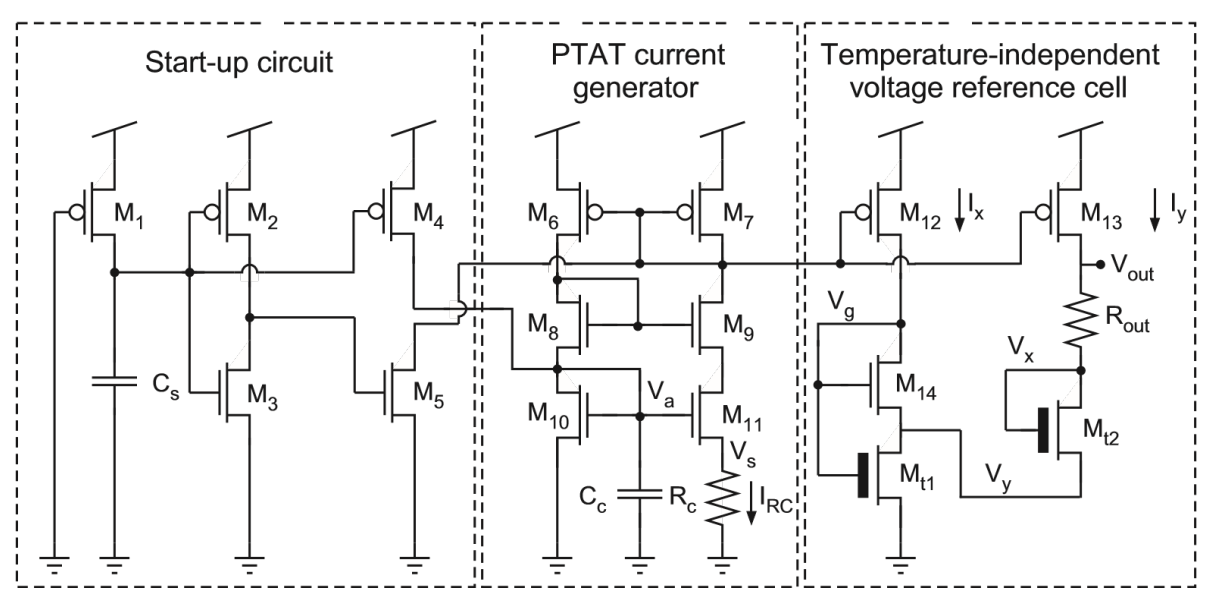

Figure 2.2: Navidi's original voltage reference cell

The new voltage reference cell is a modified version of Navidi's original circuit[11] which is displayed in figure 2.2. The only difference between 
Navidi's original circuit and the new one is the reference cell. As shown and stated previously, the start-up circuits and PTAT generators are identical. According to Navidi in the respect of figure 2.2 and allowing $M_{t 1}=M_{a}$ and $M_{14}=M_{b}$, currents through $M_{b}$ and $M_{a}$ are $I_{x}$ and $I_{x}+I_{y}$, respectively; through work he found $V_{y}$ which he noted that it can't be too large. For simplicity in the new circuit shown in Fig.2.1, transistors $M_{12}, M_{14}$, and $M_{t 1}$ are eliminated. Now labelled $M_{Z}, M_{t 2}$ is now connected to ground. Changes in performance are expected, and it may not perform as well as the original cell. However, the simplification of this reference cell enables the circuit to be used in more applications. The current $I_{y}$ flows through transistor $M_{13}$. These changes may hamper performance; however, this simplifies the cell enabling the circuit to be used in more applications. The two different cells are shown in Figure 2.3. Considering that the current flowing through transistor $M_{13}$ is $I_{y}$ which is calculated by multiplying $I_{R C}$ by a factor of $\mathrm{y}$, there is a need to consider the appropriate sizing for this transistor so that it is a better representative of sorts for the current generator. By the proper adjustment of $M_{Z}$, an output voltage greater than 1 volt can be produced. In addition, the output voltage $V_{O U T}$ is increased by the drop in voltage across the resistor $R_{O U T}$. A higher voltage can be obtained by using a small number of transistors and the advantage of the reference cell's orientation. Remember, a resistor ratio of $R_{O U T} / R_{C} \approx 6$ is required to achieve a good TC in this circuit. Additionally, by carefully altering the ratio, the temperature at which the TC is minimized can be altered to a different value while still maintaining a good TC.

Figure 2.3 shows the differences between the temperature-independent voltage reference cell displayed in Figure 2.2 to the new reference cell as shown in Figure 2.1. As stated previously, transistors $M_{12}, M_{14}$, and $M_{t 1}$ are absent in the new reference cell with the source of $M_{t 2}$ now being connected to ground and labelled as $M_{Z}$. These changes enable the output voltage to be approximately equal to the sum of the PTAT voltage and the voltage net $V_{x}$. As represented in (2.11), this is a simpler way of describing 

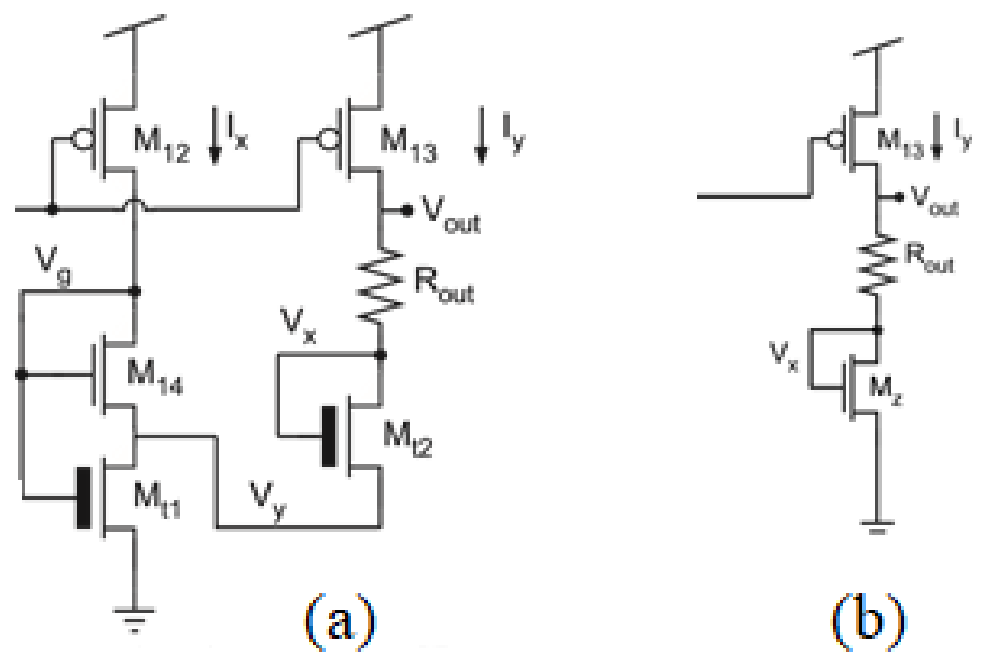

Figure 2.3: (a)Navidi's Original Cell, (b) New Cell

$(2.4)$.

$$
V_{O U T}=V_{P T A T}+V_{x}
$$

\section{$2.2 \quad$ Design Procedure and Results}

A 5-step design procedure can acquire a low TC while producing above$1 \mathrm{~V}$ voltage output using the circuit of Figure 2.1. This is based off of Navidi's procedure for his circuit as detailed in [11], and by simulating the circuit with different size ratios, it was found that these steps would be appropriate for this circuit.

1. Set $S_{11} / S_{10}$ ratio to be greater than 1 , and pick a proper size for $R_{C}$ to bias the current reference cell in the subthreshold region. Note, a large ratio will result in a bigger $R_{C}$; due to this, try not to make the ratio too large and preferably,no larger than 5.

2.Assign the appropriate transistor aspect ratios that $S_{13} / S_{Z}$ is less than

1. In addition, ensure that all transistors are in sub-threshold region of 
operation.

3. Check that the transistor lengths are large enough to not be impacted channel-length modulation.

4.Pick the midpoint, $T_{0}$, of the desired temperature range.

5.If the midpoint of the $V_{O U T}$ vs. $T$ curve is not at a specific location, $R_{C}$ can be adjusted to move $T_{0}$ to different temperatures. Also, if this adjustment to $R_{C}$ is too great, $R_{O U T}$ should be appropriately adjusted to keep the resistance ratio in check.

As stated previously, the complete voltage reference circuit of Figure 2.1 with additional connections is currently being fabricated using a standard $0.5 \mu \mathrm{m}$ CMOS technology. The voltage supply was $3.3 \mathrm{~V}$. The resistors ( $R_{C}$ and $R_{O U T}$ ) used in this circuit were connected to MUXes to allow for the future testing of the circuit with on-chip resistors or off-chip resistors. Using the design procedure shown above, the resistors needed to have a ratio of approximately six for a low temperature-dependent output. $R_{O U T}$ and $R_{C}$ were set to $3.6 \mathrm{M}$-ohms and $600 \mathrm{k}$-ohms, respectively, to achieve this ratio plus guarantee subthreshold operation. The resistance ratio is important as the output reference voltage is a function of this ratio, and the temperature dependence of these resistors seem to cancel each other out. The simulation of the sweeping of $V_{D D}$ to obtain $V_{O U T}$ was done at room temperature with transistor sizing according to Table 2.1.

Table 2.1: Circuit \#1 transistor widths \& lengths

\begin{tabular}{|l|l|l|}
\hline Transistor & Width $(\mu \mathrm{m})$ & Length $(\mu \mathrm{m})$ \\
\hline$M_{1-5}$ & 5.1 & 1.05 \\
\hline$M_{6}$ & 19.8 & 19.8 \\
\hline$M_{7}$ & 45.9 & 19.8 \\
\hline$M_{8-10}$ & 4.05 & 1.95 \\
\hline$M_{11}$ & 20.1 & 1.95 \\
\hline$M_{13}$ & 43.2 & 19.8 \\
\hline$M_{z}$ & 190.2 & 10.05 \\
\hline
\end{tabular}

Figure 2.4 shows the simulated $V_{O U T}$ for a range of $V_{D D}$. The plot shows that the output voltage begins to plateau around a supply voltage of 1.8 


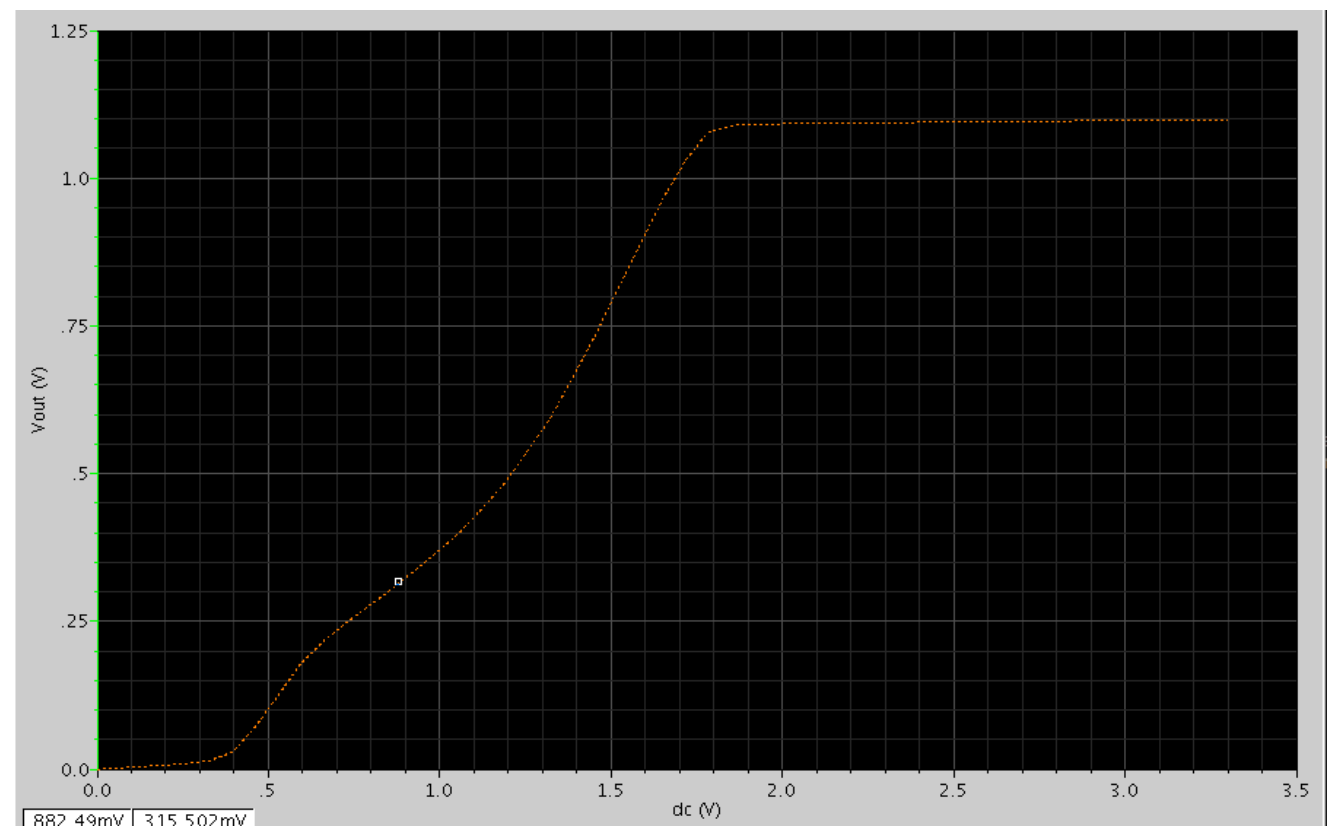

Figure 2.4: $V_{D D}$ sweep effects on $V_{O U T}$

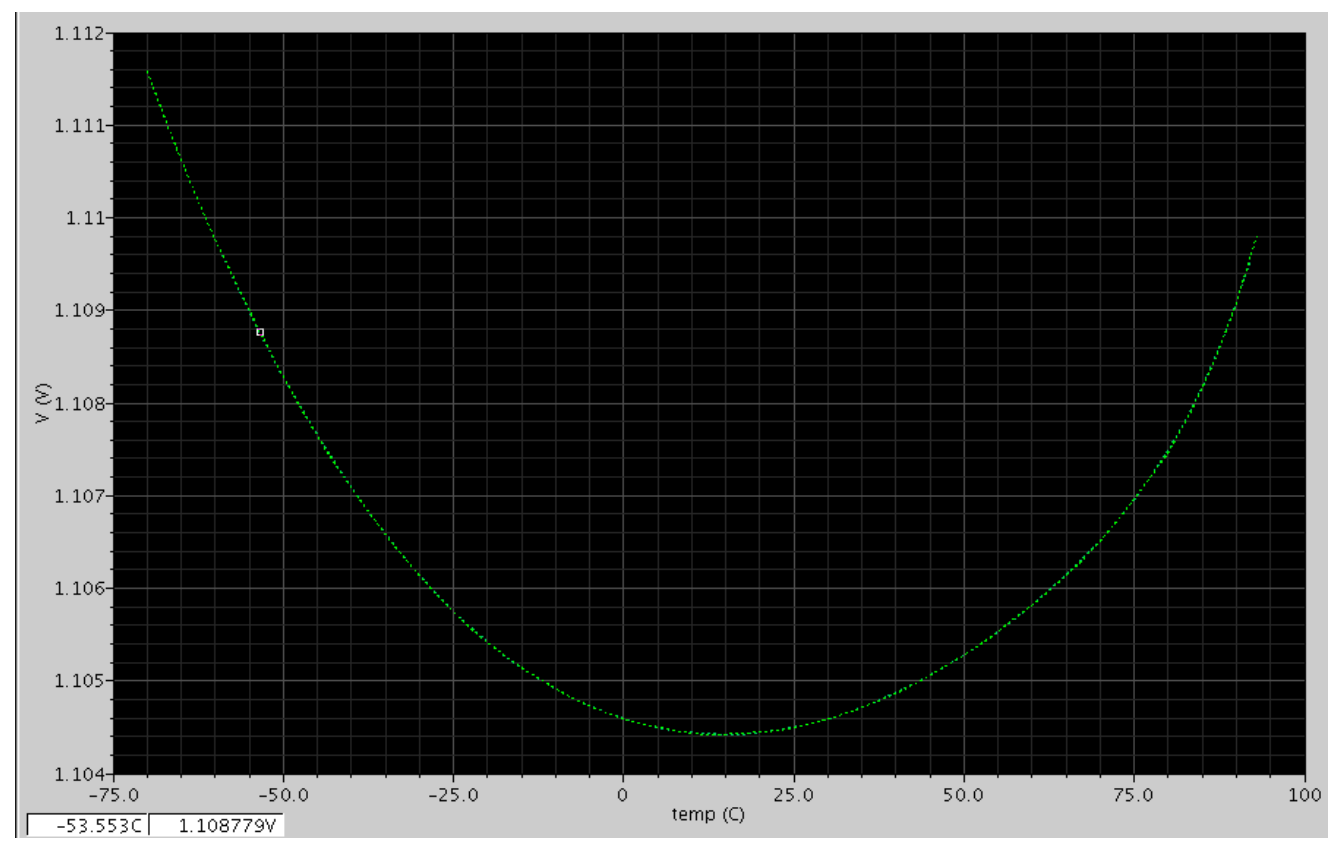

Figure 2.5: Temperature sweep effects on $V_{O U T}$ 
$\mathrm{V}$, and as $V_{D D}$ increases to $3.3 \mathrm{~V}, V_{O U T}$ is approximately $1.1 \mathrm{~V}$. Figure 2.5 shows that this circuit is able to achieve a low $\mathrm{TC}$ of $86 \mathrm{ppm} /{ }^{\circ} \mathrm{C}$ over the temperature range $\left(-70\right.$ to $\left.+88^{\circ} \mathrm{C}\right)$ through simulation. As discussed in the previous section of this chapter, this circuit can be optimized to achieve a good temperature coefficient.

\subsection{Layout of Voltage Reference Cell}

An important part of the fabrication process is the creation of a circuit layout as covered in multiple chapters in [13]. As this circuit will be created as part of an integrated circuit chip, the organization the circuit layout is important for performance. To make a layout, a representation of the circuit parts will be created in a computer program with multiple figures in this section showing parts of the representative layout of this circuit. As errors can happen during the fabrication process, two demultiplexers (DEMUXes) and a multiplexer (MUX) were added to the circuit. A MUX selects between input signals which would be sent to a single output line. Oppositely, a DEMUX uses a single input and selects one of the output lines. These devices serve as a switch so to speak, allowing for testing of the circuit with the original on-chip resistors and separate off-chip resistors to take place of resistors $R_{C}$ and $R_{O U T}$. The addition of these devices into the circuit will raise the TC of the circuit. Specifically, their addition makes the overall circuit have a $T C \approx 102 \mathrm{ppm} /{ }^{\circ} \mathrm{C}$. With the addition, the circuit needs to have a TC preferably $110 \mathrm{ppm} /{ }^{\circ} \mathrm{C}$ or less so this circuit with the additional MUXes still works as intended through simulation. This is the exact maximum preferred TC as Navidi observed for his circuit containing the original cell shown in Figure 2.3. With the addition of MUXes, the TC was expected to increase as the cell without them is approximately $86 \mathrm{ppm} /{ }^{\circ} \mathrm{C}$. As shown in Figure 2.6, half of the multiplexer input/output lines are connected to circuit pins $R_{P T A T}$ and $R_{\text {Vref(+,-) }}$.

Figure 2.6 displays the addition of MUXes in the schematic of the 


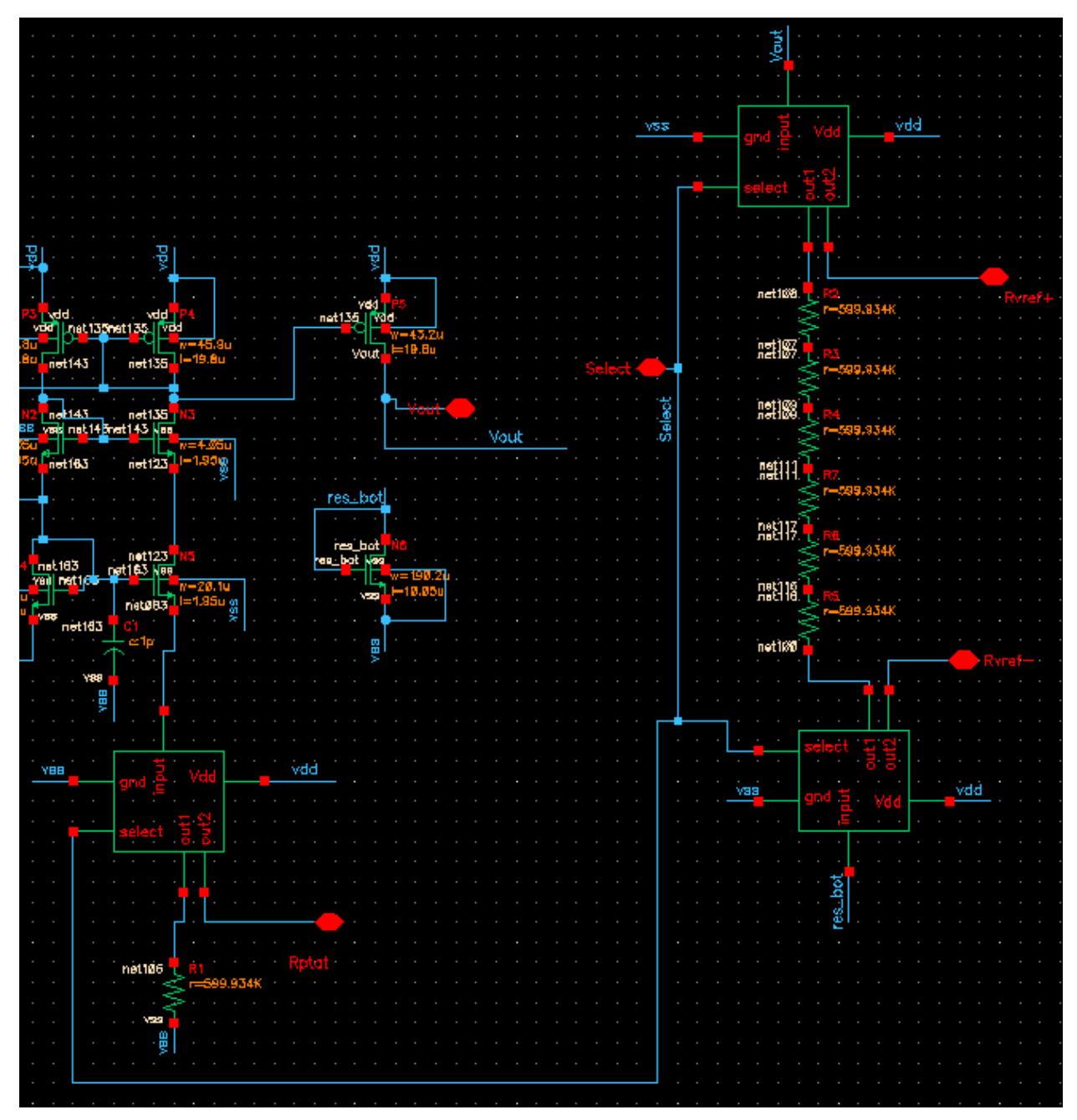

Figure 2.6: Circuit with MUXes and Pins 
circuit to separate the remainder of the circuit from the resistors. While not impactful on the circuit voltage output, the capacitors $C_{S}$ and $C_{C}$ help to stabilize the circuit. These devices have values of $3.1 \mathrm{pF}$ and $1 \mathrm{pF}$, respectively. The splitting of resistor $R_{O U T}$ into six smaller but identical resistors as shown in the figure will be represented in the layout as part of a common-centroid layout orientation.

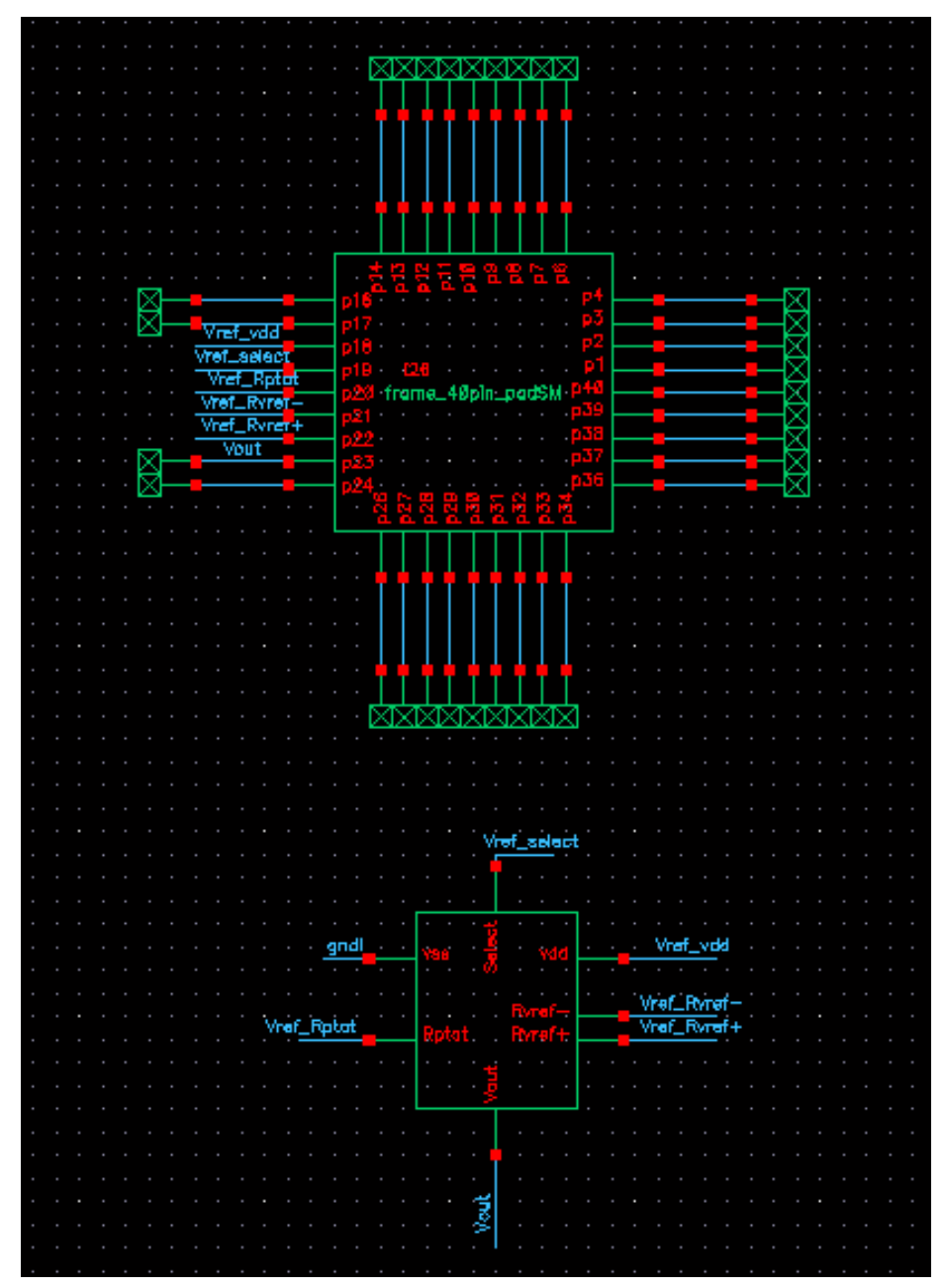

Figure 2.7: Pad Connections

Figure 2.7 presents the connections of the circuit schematic represented by a symbol block to pads of a chip. The chip connections are represented by the $V_{R E F}$ pins: $V_{d d}, V_{s s}$ (ground), Select, $R_{\text {ptat }}, R_{v r e f+}, R_{v r e f-}$, and $V_{O U T}$. 
The seven pins required only six pads as the circuit's ground can be connected to the ground of any pad. Another version of these connections is shown in a sample chip connection displayed in Figure 2.8.

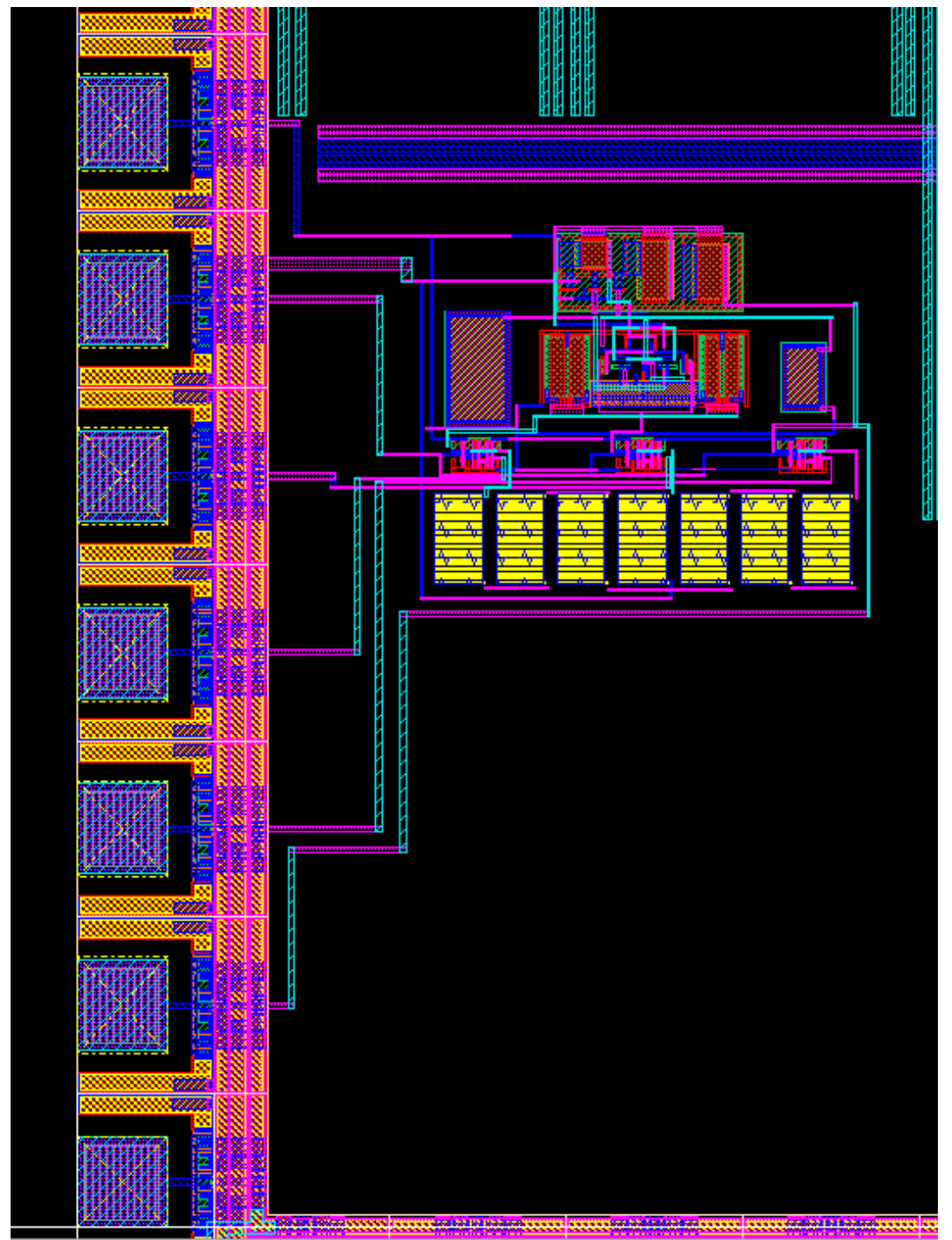

Figure 2.8: Chip Connections

Figure 2.9 is the entire layout of the PMOS transistors $M_{1-3}, M_{6,7}$, and $M_{12}$ sharing a well. Figure 2.10 is a screenshot of transistor $M_{7}$ with the width and length ratio $19.8 \mu \mathrm{m} / 19.8 \mu \mathrm{m}$ while showing the connections to the source, drain, and gate of the transistor. Surrounding the transistors, the guard rings are connected to $V_{d d}$ and the sources of the 


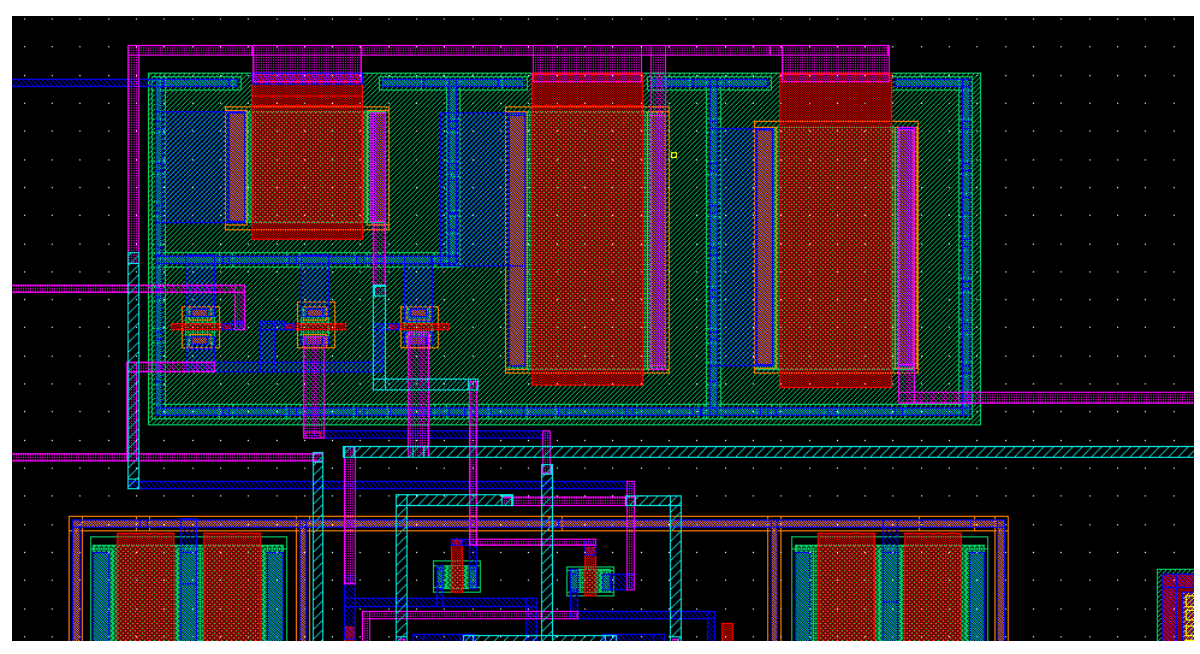

Figure 2.9: Layout of PMOS

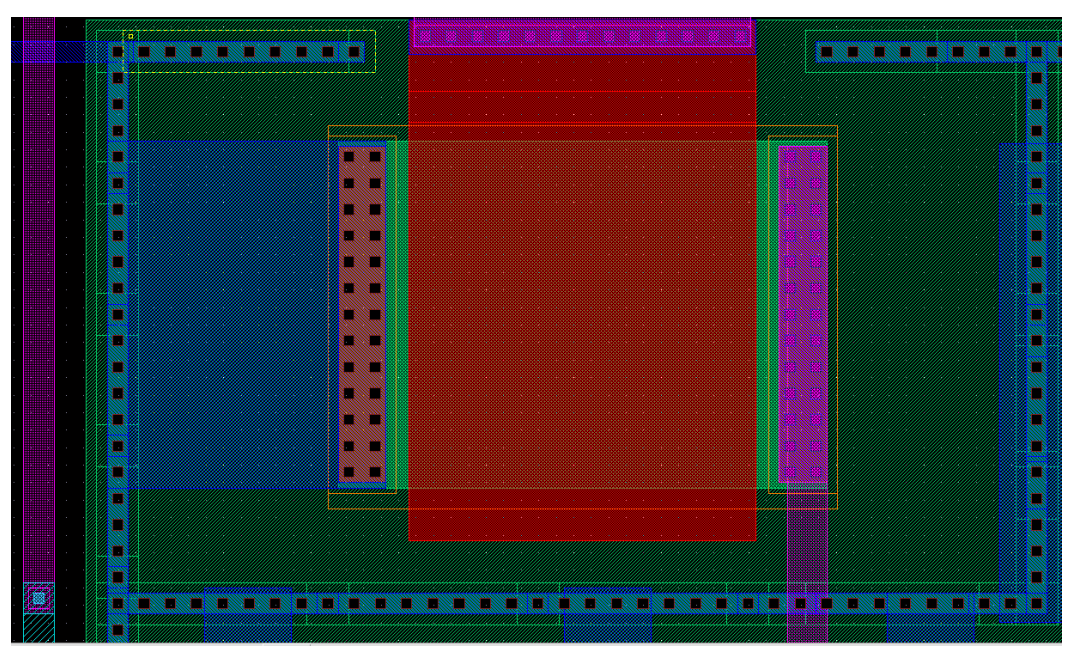

Figure 2.10: Layout of M7 
transistors; they serve as protection in these circuits with more detail contained in Figure 2.10. Traditionally in circuits, they are used to protect high-impedance nodes from surface leakage currents. Figures 2.11-15 show the layout of NMOS transistors, capacitors, resistors, and MUXes. For the NMOS transistors, the guard rings surrounding them are connected to ground, $V_{s s}$.

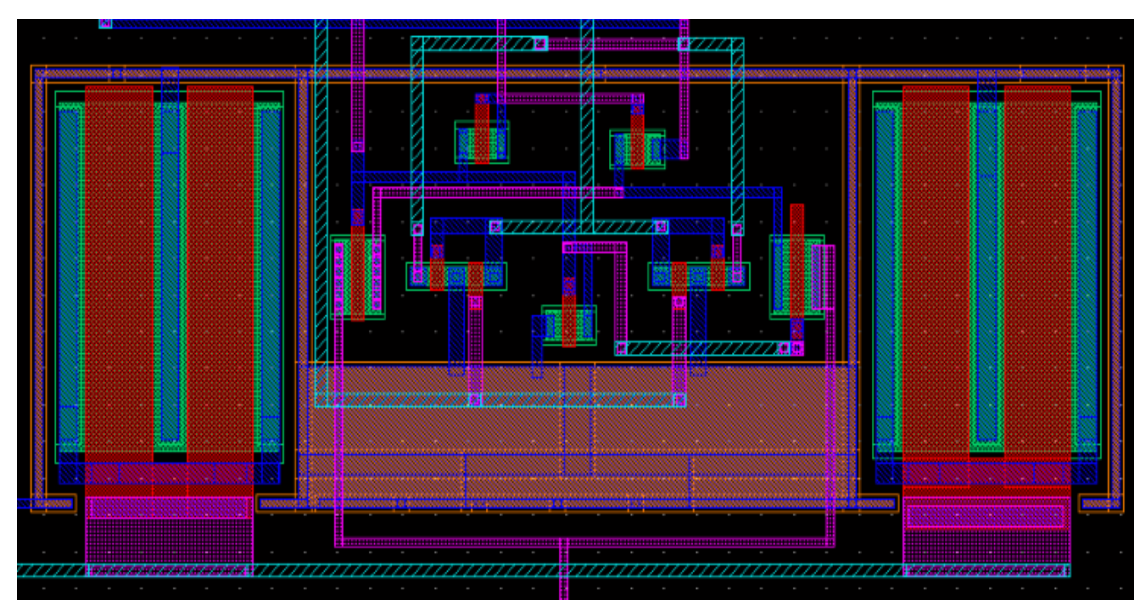

Figure 2.11: Layout of NMOS

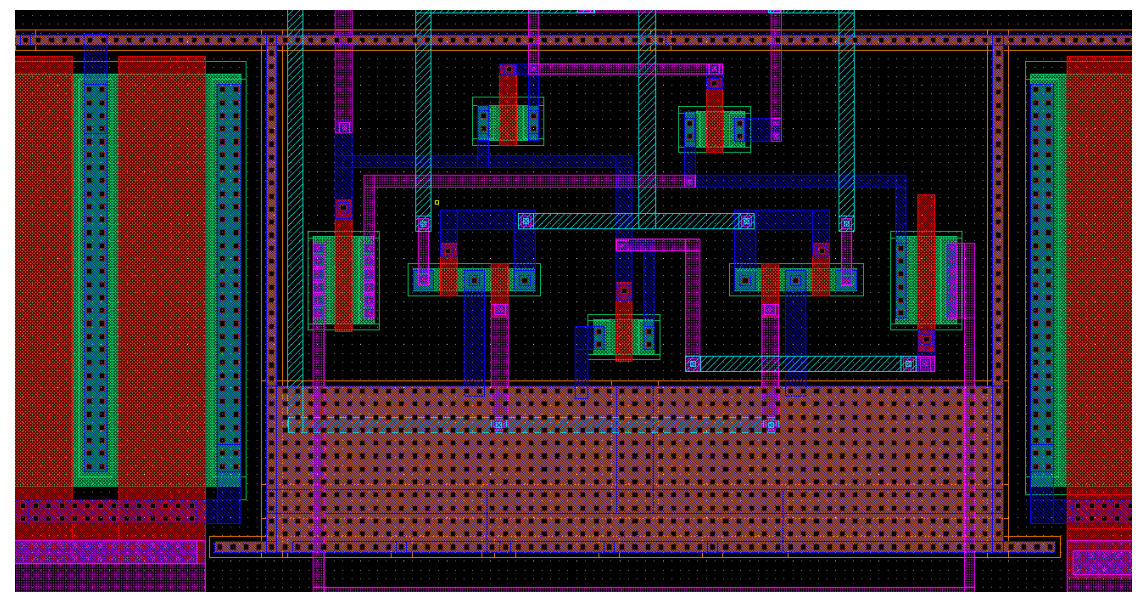

Figure 2.12: Layout of NMOS(zoomed-in)

The layout must match the schematic for a successful fabrication. Additionally while it may match, issues can cause slight errors post-fabrication. 


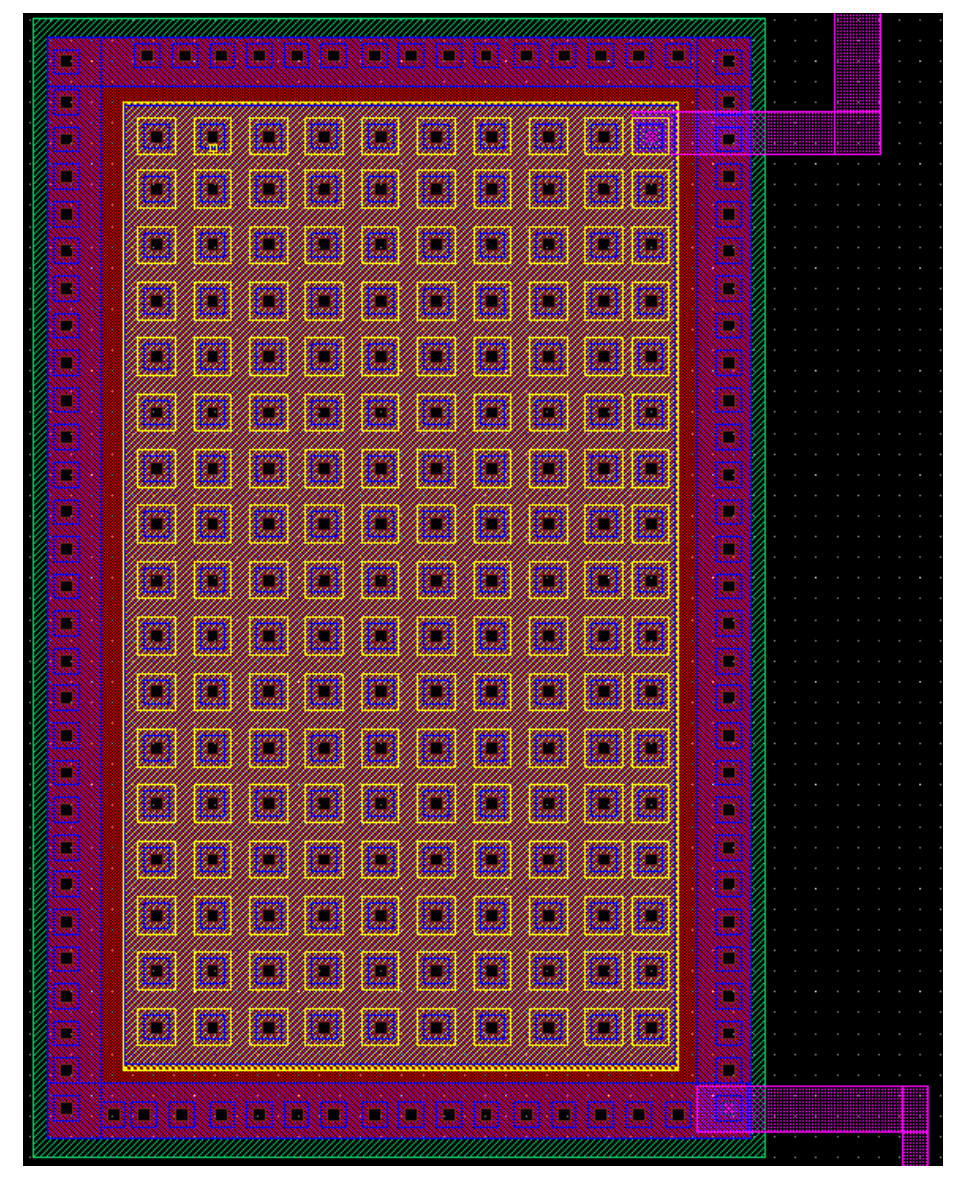

Figure 2.13: Layout of Capacitor $C_{s}(3.1 \mathrm{pF})$

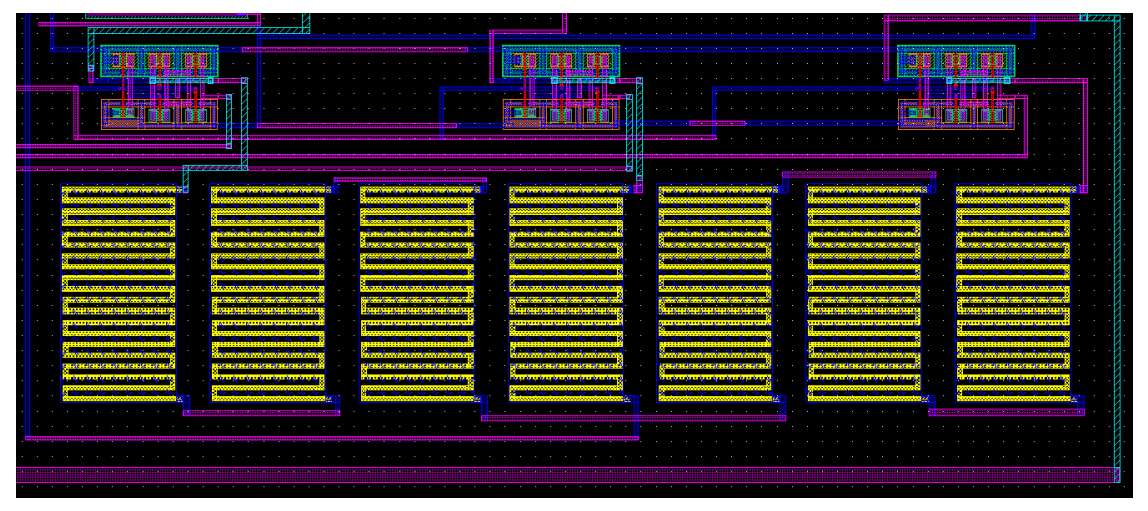

Figure 2.14: Layout of Resistors 


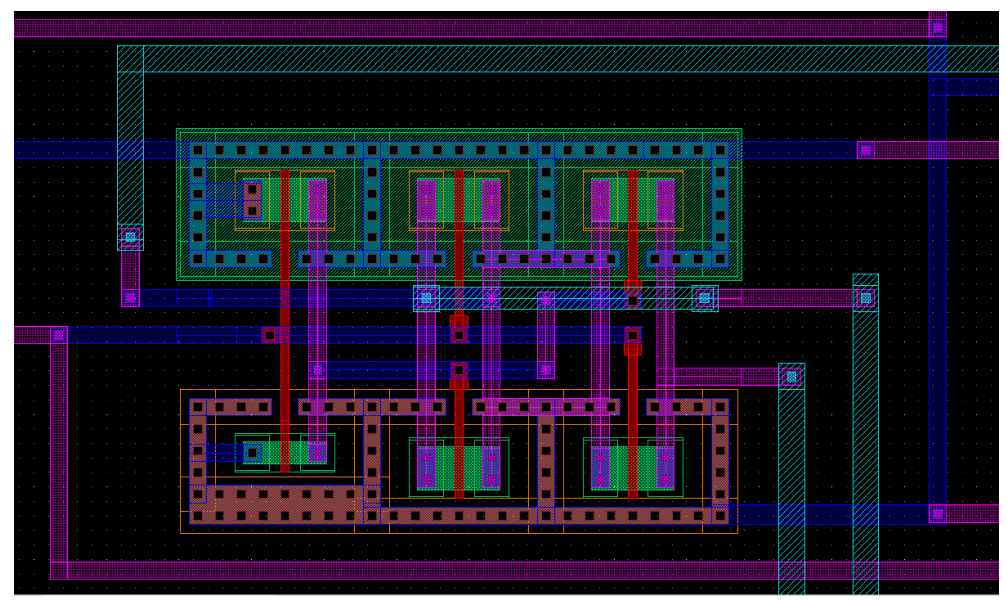

Figure 2.15: Layout of a MUX

Issues may be caused by the materials used by the foundry. Pre-fabrication issues involve the layout, itself. Any affects caused by mismatch or parasitics might impact the performance of the circuit. Methods shown in the layout figures above display examples of grouping transistor types together, fingering, and common centroid layout. As shown in the layout figures, specifically Figure 2.15, each MUX consists of both PMOS and NMOS transistors in close proximity and connected together. While not major for this circuit, grouping those transistors with the other transistor groups may help with performance of the circuit post-fabrication. The common-centroid method is prevalent in the grouping of the resistors representing $R_{C}$ and $R_{O U T}$. Considering $R_{O U T}=6 \times R_{C}$, seven equal resistors were created for both the schematic and layout. With $R_{C}$ placed in the middle, the other six resistors, which represent $R_{O U T}$, were placed on both sides with equal distance between one another as shown in Figure 2.14. Specifically, parasitic capacitance exists when electronic components are in close proximity to each other, and a prime example of parasitics would be the crossing of a circuit net (i.e. metal 2) over another net (i.e. metal 1) as shown in Figure 2.16. With more practice in regards to the formation and orientation of a circuit layout, a better performance can be achieved with lesser parasitics and other layout issues. 


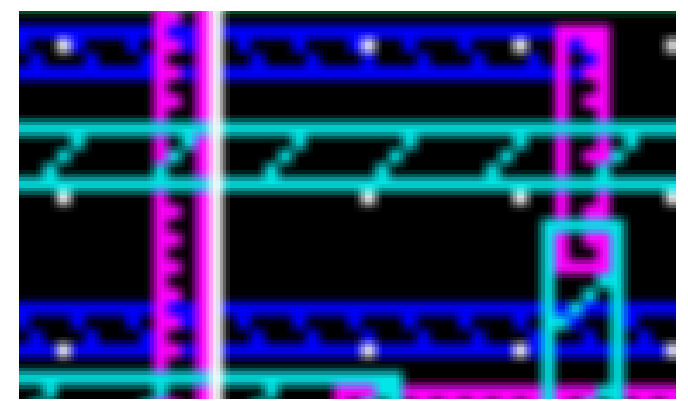

Figure 2.16: Parasitics caused by overlapping of metals

While layout orientation is important for performance, the important part of layout is that it matches the schematic and passes design rules through a series of tests: Design Rules Check, Extraction, and Layout Vs. Schematic. Once it passes these three tests, the circuit should at least work when it comes back from the foundry, provided no other issues.

\subsection{Results of first reference cell simulation}

The results of this low voltage reference cell is shown in Table 2.1 while also comparing to other works. By simulation, the output voltage of the layout version of this reference cell is $1.1 \mathrm{~V}$ with a $\mathrm{TC}$ of $102 \mathrm{ppm} /{ }^{\circ} \mathrm{C}$ as shown in figures 2.17-18 while consuming $1.25 \mu \mathrm{W}$ of power as compared to the circuit's original $86 \mathrm{ppm} /{ }^{\circ} \mathrm{C}$ simulation. 


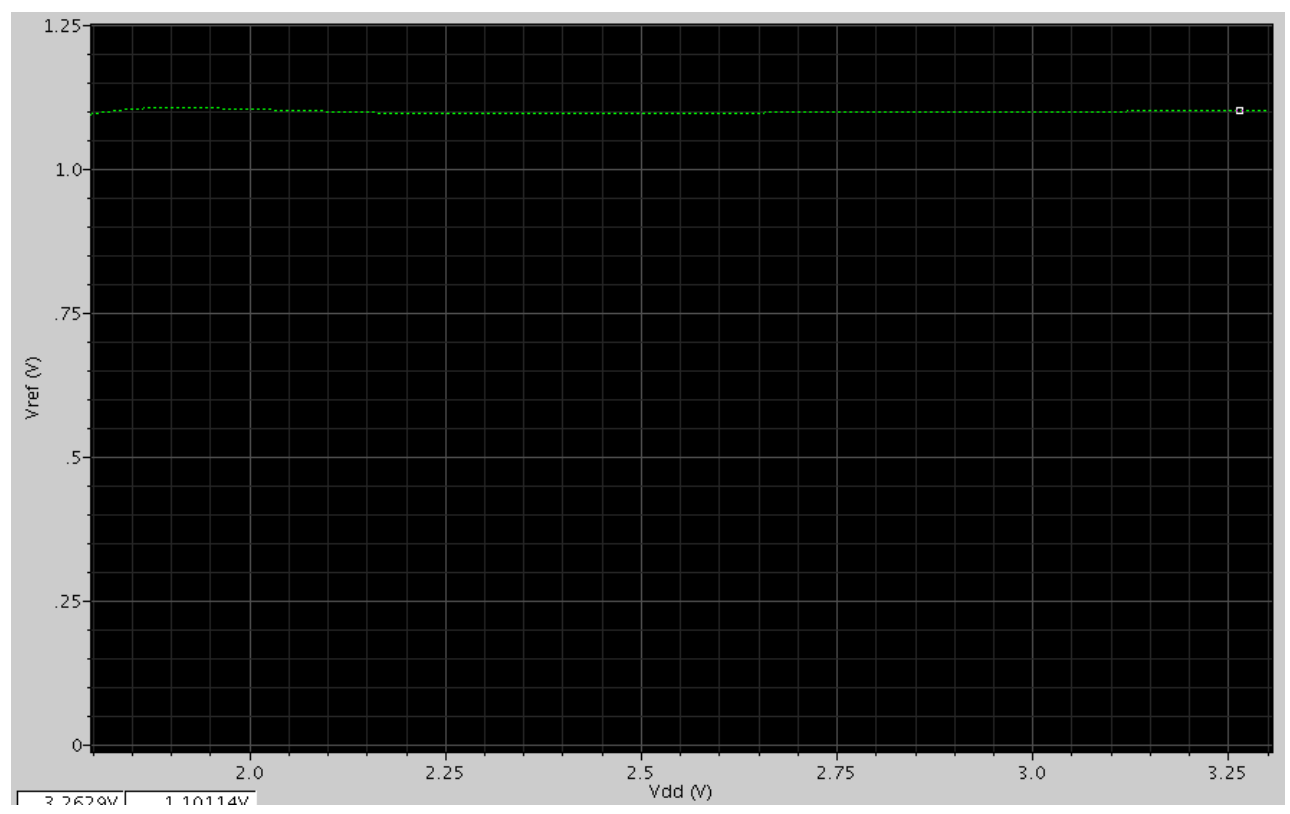

Figure 2.17: Output Voltage of $V_{R E F}$

As displayed in Table 2.2, the works are comparable. Although they were designed in different processes, all managed to obtain a Temperature Coefficient less than $110 \mathrm{ppm} /{ }^{\circ} \mathrm{C}$, and a power consumption smaller than $1.5 \mu \mathrm{W}$. Comparing this work to Navidi's, both cases have a supply voltage margin of $1.5 \mathrm{~V}$ where they produce the output voltages as shown. Major differences include the $0.35 \mu \mathrm{m}$ process's ability to have a maximum power supply voltage $V_{D D}$ of $2.5 \mathrm{~V}$ whereas the 0.5 micron allows up to $3.3 \mathrm{~V}$. Navidi's TC is slightly less than half of the TC accomplished by my work as well as accomplishing a slightly lower power consumption of 1.11 microwatts. My circuit has a power consumption of approximately 1.25 microwatts according to simulation, and it would be expected that a smaller TC would increase the power consumption required for the circuit regardless of the fabrication size process. The $0.35 \mu \mathrm{m}$ process is notable for its ability to produce quality circuits with lower power consumption as compared to the $0.5 \mu \mathrm{m}$. Navidi's cell did produce a higher voltage output, but I'm not too concerned about that. 


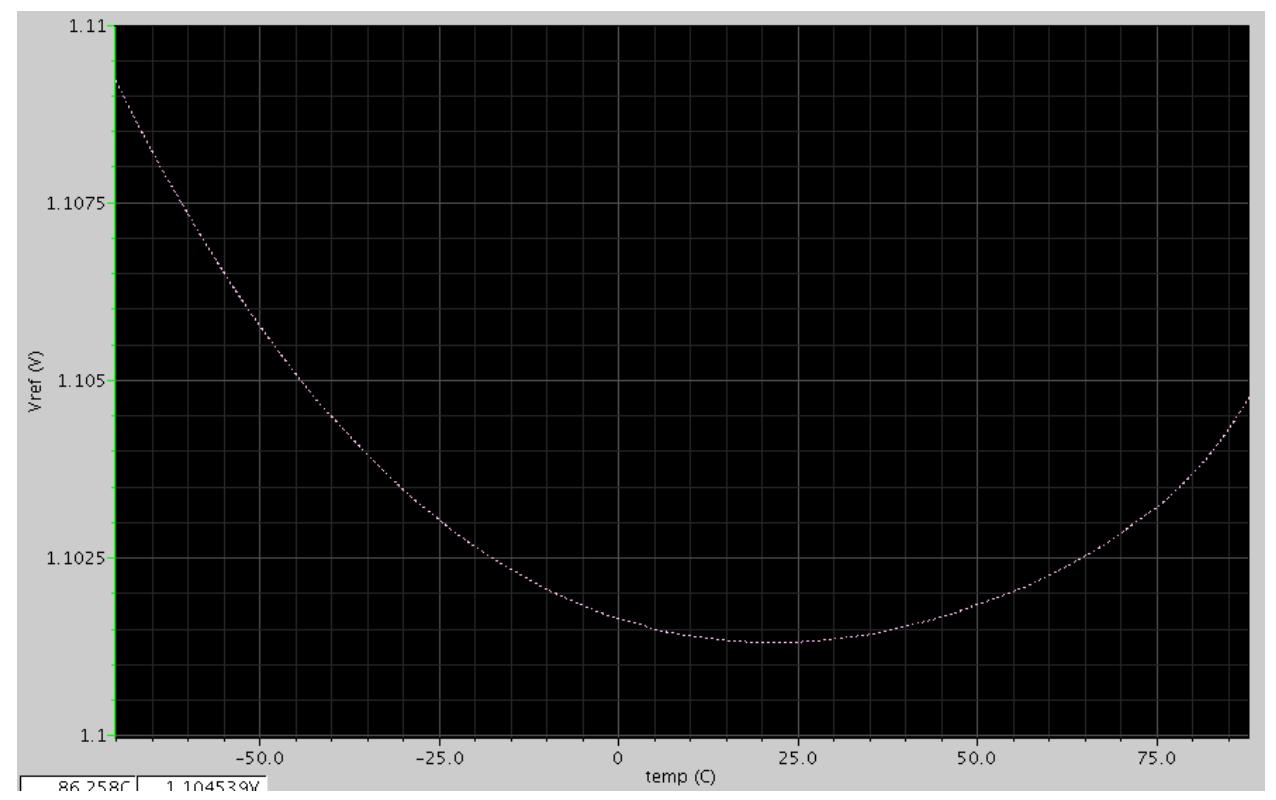

Figure 2.18: Graphing of TC

Table 2.2: Comparing circuit \#1 work with other works

\begin{tabular}{|l|l|l|l|l|l|l|}
\hline Work & Proc. & $\begin{array}{l}V_{D D} \\
(\mathrm{~V})\end{array}$ & $\begin{array}{l}V_{\text {OUT }} \\
(\mathrm{V})\end{array}$ & $\begin{array}{l}\mathrm{TC} \\
\left(\mathrm{ppm} /{ }^{\circ} \mathrm{C}\right)\end{array}$ & $P_{\text {cons }}$ & $\begin{array}{l}\text { Range } \\
\left({ }^{\circ} \mathrm{C}\right)\end{array}$ \\
\hline$\# 1$ & $0.5 \mu \mathrm{m}$ & $1.8 \sim 3.3$ & 1.10 & 86 & $1.25 \mu \mathrm{W}$ & {$[-7088]$} \\
\hline$\# 1(2.3)$ & $0.5 \mu \mathrm{m}$ & $1.8 \sim 3.3$ & 1.10 & 102 & $1.25 \mu \mathrm{W}$ & {$[-7088]$} \\
\hline Navidi & $0.35 \mu \mathrm{m}$ & $1 \sim 2.5$ & 1.52 & 42 & $1.11 \mu \mathrm{W}$ & {$[-7085]$} \\
\hline$[14]$ & $0.18 \mu \mathrm{m}$ & $1.4 \sim 3.6$ & 1.25 & 73 & $35 \mathrm{pW}$ & {$\left[\begin{array}{ll}0 & 100\end{array}\right]$} \\
\hline
\end{tabular}

Another category of comparison is that the temperature range in the circuit was simulated to obtain TC results as this work was tested at a slightly larger range than Navidi's, and this was [-70 88] as compared to [-70 85]; this tells me that this is an appropriate range for this circuit. Adding the fact that a layout of this circuit was created so the circuit can be fabricated as it is currently undergoing, the circuit was enjoyable to design plus there is satisfaction for the results of the simulation as this new circuit was comparable with Navidi's. An intention of future work would be to measure the new circuit after it is fabricated to compare it with the simulation in respect to the output voltage, temperature coefficient and 
power consumption. If the circuit doesn't perform as well post-fabrication as compared to the simulation with the on-chip resistors, improvements may be required in layout such as better common centroid techniques; however, additional testing using off-chip resistors to connect with the $R_{V r e f}$ and $R_{P T A T}$ pins as well as the ground should be completed first. Different sizes of resistors would be applied to observe whether or not the TC and power consumption can be lowered. 


\section{Chapter 3}

\section{Reference Cell with below 1V Output}

\subsection{Background}

Chapter 3 focuses on an adaptation of voltage reference cell originally designed by Ken Ueno and others in the 0.35 micron process described in [9] and designing the circuit to function the 0.5 micron. Stated previously, an example area of research in microelectronics is the development of ultralow power LSIs that operate in the subthreshold region of MOSFETs. These devices demand ultra-low power due to poor energy sources such as a modern cell phone battery.

As a step toward LSIs, Ueno aimed to design a voltage reference circuit that can operate with an ultra-low current within the range of several tens of nano-amps or less with considerations to problems as listed in Chapter 1. To achieve this, the circuit was designed to operate in the MOSFET subthreshold region of operation. To solve those issues, the group developed a new voltage reference circuit that can work with a power dissipation smaller than a micro-watt as well as smaller line and temperature sensitivity than the circuit designed by Leung previously stated in Chapter 1 . The small line sensitivity was obtained by placing all transistors in subthresh- 
old operation except for one labelled as $M_{R}$ as shown in Figure 3.1. This circuit contains no resistors; to act as a substitute, that single transistor was operated in the triode region to mimic a resistor. The designed circuit achieves two voltages having opposite temperature coefficients (TC's); to better explain, a MOSFET threshold voltage with a negative TC and a multiple of the thermal voltage with a positive TC. Adding these two voltages together produces an output voltage with TC that is approximately zero. Equal to the threshold voltage of a MOSFET at $0 \mathrm{~K}$, the output voltage is approximately $745 \mathrm{mV}$ for the MOSFETs in Ueno's circuit. Designed appropriately, the output voltage has minimal reactions to temperature change and variations in supply voltage; however, fabrication processes can still impact the circuit. By utilizing the nature of the reference voltage, which changes with the process conditions of threshold voltage in each LSI chip, the circuit can be used in on-chip process compensation systems. In Ueno's circuit, a small $\mathrm{TC}$ of $7 \mathrm{ppm} /{ }^{\circ} \mathrm{C}$ was achieved.

Since this will be designed for the $0.5 \mu \mathrm{m}$ process, the circuit for this process would be done in a way similar to Ueno's circuit as contained in Figure 3.1 using standard thin-oxide transistors. This reference circuit contains two sub circuits for a current source and bias voltage. According to Ueno and his group, the current source sub circuit serves as a modified $\beta$ multiplier self-biasing circuit with the transistor $M_{R}$ operating in the triode region. This orientation enables the triode-operated transistor to serve as a resistor with the gate connected to the output of the reference cell. The current, $I_{p}$, is generated by this sub circuit, and through the use of PMOS current mirrors, it is replicated in the bias voltage sub circuit which produces output voltage $V_{R E F}$. The op amp used in this circuit is a differential op amp as shown in Figure 3.2. The bias-voltage sub circuit consists of transistor $M_{4}$ and two source-coupled pairs $\left(M_{3}\right.$ and $M_{6}, M_{5}$ and $M_{7}$ ). The gate-source voltages of $M_{3}-M_{7}$ in the bias-voltage sub circuit form a closed loop with the current source sub circuit's $M_{R}$. 
All the MOSFETs except for $M_{R}$ are operated in the subthreshold region. For this circuit as stated previously, The MOS resistor is operated within the strong-inversion, deep-triode region of transistor operation. The circuit generates two voltages with a negative TC and a positive TC and combines them to produce a constant voltage with a TC near zero.

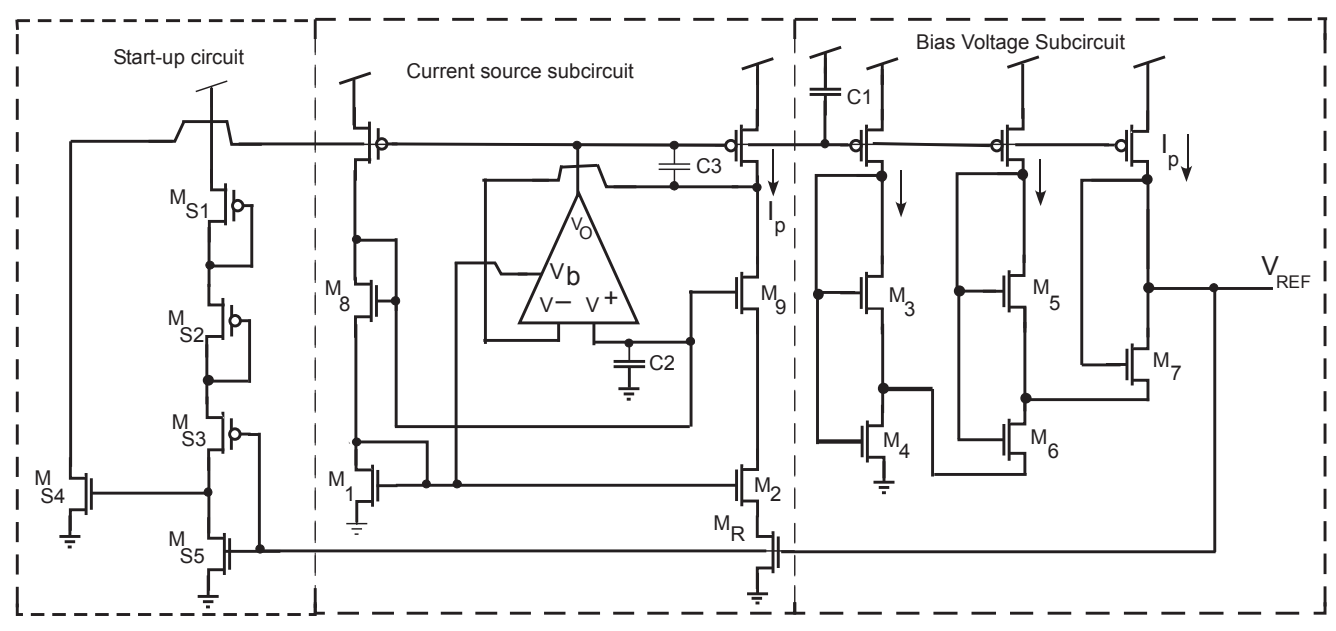

Figure 3.1: Ueno-based Circuit

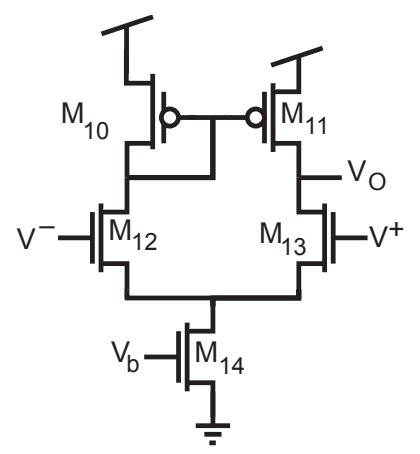

Figure 3.2: Differential Op Amp

The subthreshold drain current $I_{D}$ of a MOSFET is an exponential function of the drain-source voltage, $V_{D S}$, and the gate-source voltage, $V_{G S}$. According to Ueno, this current is obtained by the equation labelled (3.1).To explain the symbols in this equation, $\mathrm{K}$ assigned as the aspect width/length ratio of the transistor, $\mu$ is the carrier mobility, $C_{O X}$ is the 
gate-oxide capacitance, $V_{T}$ is the thermal voltage, $V_{T H}$ is the threshold voltage of a MOSFET, and $\eta$ is the subthreshold slope factor. For a $V_{D S}$ that is larger than $0.1 \mathrm{~V}$, the resulting current is nearly independent of the drain-source voltage. Ueno exemplified this case in (3.2).

$$
\begin{gathered}
I_{D}=\left(K I_{0}\right)\left(\exp \left(\frac{\left(V_{G S}-V_{T H}\right)}{\eta V_{T H}}\right)\left(1-\exp \left(\frac{-V_{D S}}{V_{T}}\right)\right)\right. \\
I_{0}=\mu C_{O X}(\eta-1) V_{T}^{2} \\
I_{D}=\left(K * I_{0}\right)\left(\exp \left(\frac{\left(V_{G S}-V_{T H}\right)}{\eta V_{T H}}\right)\right)
\end{gathered}
$$

In the current-source circuit, the gate-source voltage in transistor $M_{1}$ is approximately equal to the sum of the gate-source voltage in $M_{2}$ and the drain-source voltage in the MOS resistor as claimed in (3.3). Due to the currents in $M_{1}$ and $M_{2}$ being approximately equal to one another, (3.3) can be re-imagined as (3.4) representing the $V_{D S}$ in $M_{R}$.

$$
\begin{gathered}
V_{G S 1}=V_{G S 2}+V_{D S R} \\
V_{D S R}=\eta V_{T} \ln \left(K_{2} / K_{1}\right)
\end{gathered}
$$

Considering that the MOS resistor $M_{R}$ is operated in a strong-inversion, deep-triode region, the resistance $R_{M R}$ can be calculated as shown in (3.6). By mixing equations (3.4-6), the equation (3.6) can be obtained for the PMOS current $I_{P}$. An interesting note is that (3.7) for $I_{P}$ may hold true even prior to the addition of the op amp and $M_{8,9}$, and this is based upon allowing the $M_{P 1}$ drain connect to the $M_{1}$ drain and the $M_{P 2}$ drain connect to the $M_{2}$ drain and the gates of all PMOS transistors including itself. Also, as $M_{R}$ is designed to mimic a resistor, a resistor in its place would have to be significantly large in order to produce similar results. 


$$
\begin{gathered}
R_{M R}=\frac{1}{K_{R} \mu C_{O X}\left(V_{R E F}-V_{T H}\right)} \\
I_{P}=\frac{V_{D S R}}{R_{M R}}=K_{R} \mu C_{O X}\left(V_{R E F}-V_{T}\right) \eta V_{T} \ln \left(K_{2} / K_{1}\right)
\end{gathered}
$$

Depending on circuit set-up, the current $I_{P}$ can have a value within the picoamp-to-nanoamp range. Remember, the gate of $M_{R}$ as its gate voltage is equal to $V_{R E F}$ also has a factor in how this transistor performs. A good note is that the current should be small, regardless. Within the bias-voltage circuit, the gate-source voltages $V_{G S 3-G S 7}$ of the transistors $M_{3-7}$ would create a closed loop and create multiples of $I_{P}$ such that $3 I_{P}$ and $2 I_{P}$ in the loop.

As a result, the output voltage of the circuit is observed in (3.8) with consideration to the possibility that any sort of mismatch between the threshold voltages of the transistors can be ignored. Furthermore, this equation assigns that the output voltage $V_{R E F}$ is a sum of the gate-source voltages. Equations (3.9) and (3.10) show a threshold voltage calculation according to Ueno and a way to calculate the Temperature Coefficient.

$$
\begin{gathered}
V_{R E F}=V_{G S 4}+V_{G S 6}+V_{G S 7}-V_{G S 3}-V_{G S 5} \\
V_{T h}=V_{T h 0}-\kappa T \\
T C=\left|\frac{d V_{R E F}}{d T}\right|
\end{gathered}
$$

Through additional work, Ueno obtained (3.11), and this equation shows that the circuit generates a reference voltage equivalent to the threshold voltage of a transistor at $0 \mathrm{~K}$. Considering equations (3.7), (3.8), and (3.9), the current $I_{p}$ is approximately the value obtained in (3.12) due in part largely by the appropriate transistor width/length ratios and the kappas according to Ueno. 


$$
\begin{gathered}
V_{R E F}=V_{T h 0} \\
I_{P}=K_{R} \mu C_{O X} \kappa T \eta V_{T} \ln \left(K_{2} / K_{1}\right)
\end{gathered}
$$

The circuit consists of an op amp, start-up circuit, and three capacitors added to the PMOS and $M_{1-7}$ NMOS in the circuit as shown in figure 3.1.1. Transistors $M_{8-9}$ serve as a current mirror in addition to $M_{10-14}$ which collectively act as a differential amplifier; combined, these transistors are intended to reduce the line sensitivity of the circuit. The start-up circuit consists of transistors $M_{15-19}$ which help to avoid the stable state in the zero-bias condition. The sizing of the transistors in both additions are important in respect to reference cell operation. Capacitors $C_{1}, C_{2}$, and $C_{3}$ prevent parasitic oscillation and noise disturbances from impacting the overall performance of the circuit. Adjustments of the transistors in the circuit are key to accomplishing a circuit with low TC and low power. Specifically, the PMOS do not need to have the same width/length ratios. In the circuit designed for the $0.5 \mu \mathrm{m}$ process, they are sized accordingly in respect to NMOS $M_{1-7}$. Specifically, $M_{1-7}$ are detailed in Table 3.1 of Section 3.3 in terms of their respective widths and lengths and along with the transistor operating in the triode region labelled $M_{R}$.

\subsection{Design Procedure}

After reading Ueno's paper and simulating the circuit, I would like to add some key information to the design of this circuit in the half micron process which I observed and followed.

1. Appropriately size transistors $M_{1-7}$. Regardless of their widths, try to keep the transistor lengths the same value for all transistors. The width/length ratios for $M_{1-3,5}$ should be large For a general range, let $S_{2}=$ 
(4-5) $\times S_{1}$. For best performance, $S_{3}=S_{5}$. Transistors $M_{4,6,7}$ will be small compared to the others; set $S_{4}=S_{6}$, with width/length ratio between 1.5 and 3. Set $M_{7}$ appropriately, $S_{7} \approx(0.95-2) \times S_{4,6}$. This approximation considers the size of $M_{P 5}$ which has its drain serving connected electrically to the gate and drain of $M_{7}$. This connection also outputs the reference voltage and controls the gate of $M_{R}$.

2. Decrease the width/ length ratio of transistor $M_{R}$ to be between 0.03 and 0.02 . For example, a ratio of $4.05 \mu / 191.1 \mu$ is approximately equal to 0.0212 . The smaller the ratio the better as it gives more lee-way when adjusting other portions of the circuit as to keep $M_{R}$ operating in the triode region. However for costs, keep sizing appropriate when possible.

3. Size the $I_{P}$ PMOS accordingly by considering the size of the appropriate NMOS transistor connected "electrically" to them. A PMOS transistor should have a similar size ratio to the corresponding NFETs; for example, a range of 0.9 to 1.1 times the associated NFET for $M_{P 1-4}$ - Consider the sizes of $M_{4,6,7}$ when designing the width/length ratio for $M_{P 5}$. A good range of consideration would be $S_{P 5}=(5-12) S_{7}$.

4. After choosing the op amp, test it by making adjustments to each transistor inside it and the start-up circuit. The purpose of these is to minimize line sensitivity which in turn helps the temperature coefficient of the circuit. Regarding the op amp used in this paper, sizes were considerably small compared to the major portions of the circuit. The inputs feeding into the op amp plus and minus ports can be switched with one connected to the drain of $M_{P 2,9}$ and the other to the gates of $M_{8,9}$ or vice-versa. As a good note for my circuit orientation, the size comparison ratio of $M_{10,12}$ to $M_{11,13}$ to be 3 to 1 as a workable range.Also, $M_{14}$ had a similar size to $M_{10,12}$.

5. Set $M_{8}$ to be larger than $M_{9}$. As $M_{8-9}$ serve as current mirror. This aids the circuit considering the large difference in ratio between $M_{1}$ and $M_{2}$. For example if $M_{9}=3 \mu / 3 \mu$, setting $M_{8}=60 \mu / 3 \mu$ or $20 * S_{9}$ would be an appropriate size difference. Regardless, have one significantly larger 
ratio than the other. After this, re-adjust $M_{R}$ if necessary.

6. If a specific midpoint temperature is desired, adjust the current mirror PMOS and $M_{3-7}$ accordingly.

7. Also considering (3.7) for simulation, an appropriate reference output voltage would be between $0.75-1 \mathrm{~V}$ for this research with the aim to be close to $800 \mathrm{mV}$.

In this paper, $S_{P 1}=S_{1}, S_{P 2} \geq S_{2}, S_{P 3} \leq S_{3}, S_{P 3}=S_{P 4}$, and $S_{P 4} \approx 5 * S_{7}$. As stated similarly in step 4 , simulate the whole circuit while adjusting the op amp and start-up circuit ratios, and when the output voltage noticeably begins to stabilize over a specific temperature range, anyone completing this circuit would be on the right track. Keep in mind that multiple adjustments may be needed as any adjustment on one transistor may need to be counter-balanced by adjusting another one appropriately.Also, this depends on the op amp and start up circuit set-up.

Like the previous circuit, the TC will be obtained by simulating the output reference voltage over the range in temperature as a graph. Consider the graph's low point, in other words, midpoint temperature. After this, pick a suitable range, and obtain the maximum and minimum values of $\mathrm{dV} / \mathrm{dT}$. Subtract the minimum from the maximum; then, divide by the minimum.

Another additional thing would be how the subthreshold region is defined. This region is where the transistor operates below threshold voltage (approximately $0.7 \sim 0.8 \mathrm{~V}$ ) and has a drain voltage greater than zero. In contrast, the triode region of a transistor is the region in which the drain's source current becomes strongly dependent on the transistor drain-source voltage. With a gate-source voltage larger than the threshold voltage, the drain-source voltage must be larger than the difference of $V_{G S}-V_{T}$ [16]. In the simulation, the values of these voltages and currents were obtained, and as checked, $M_{R}$ was operating in the triode region, and the others were operating in the subthreshold. 


\subsection{Results and Comparison}

\begin{tabular}{|l|l|l|}
\hline Transistor & Width $(\mu \mathrm{m})$ & Length $(\mu \mathrm{m})$ \\
\hline$M_{1}$ & 60 & 3 \\
\hline$M_{2}$ & 241.05 & 3 \\
\hline$M_{3}, M_{5}$ & 181.05 & 3 \\
\hline$M_{4}, M_{6}$ & 6 & 3 \\
\hline$M_{7}$ & 6 & 3 \\
\hline$M_{R}$ & 4.05 & 191.1 \\
\hline
\end{tabular}

Table 3.1: Circuit \#2 transistor widths and lengths

Appropriate sizing of the PFETs, op-amp, and start-up circuit in consideration of the NFETs described in Table 3.1 can aid in achieving a low temperature coefficient. A test run is shown in figures 3.3 and 3.4 regarding the obtained output voltage and $\mathrm{TC}$ of the voltage reference cell that produced a $V_{\text {OUT }}$ of $0.805 \mathrm{~V}$ and a $\mathrm{TC}$ of $36.1 \mathrm{ppm} /{ }^{\circ} \mathrm{C}$ while being supplied with $3.3 \mathrm{~V}$ and $2.81 \mathrm{nW}$ of power consumption.

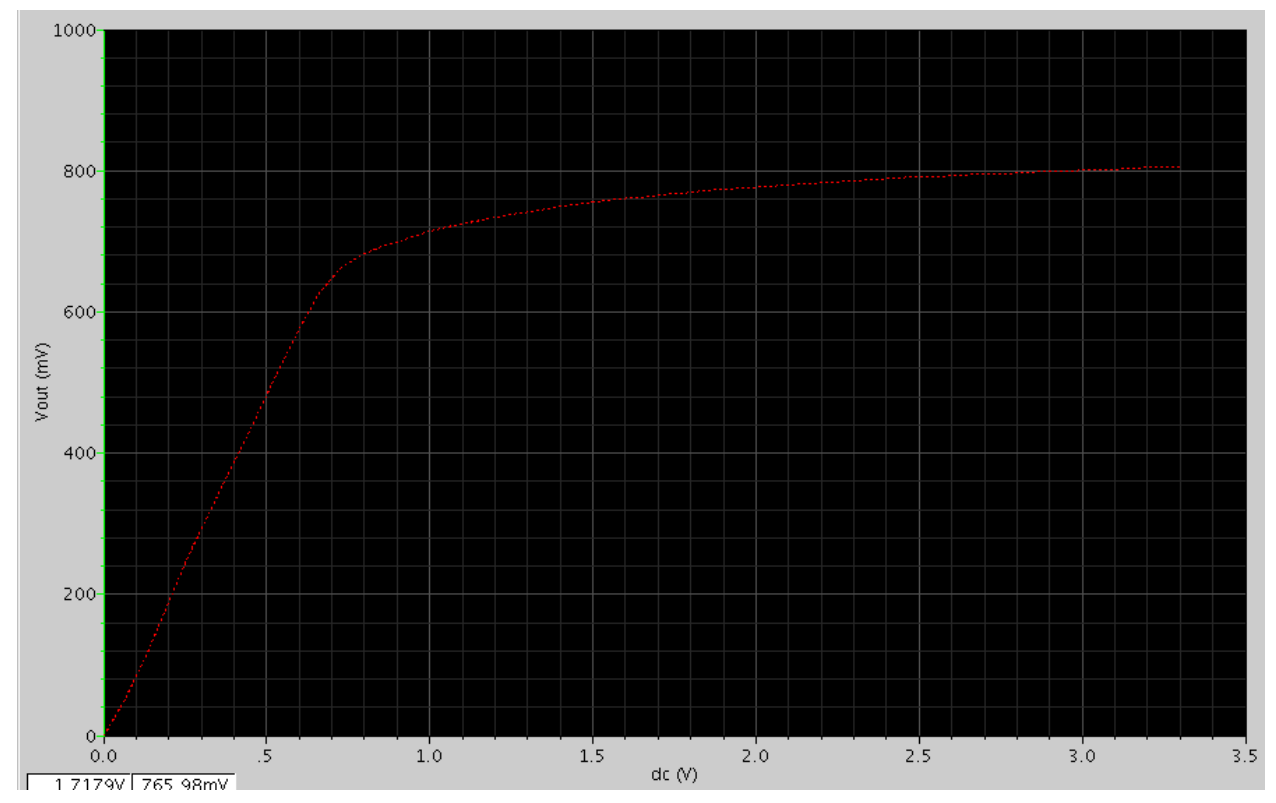

Figure 3.3: $0.5 \mu \mathrm{m}$ Output Voltage 


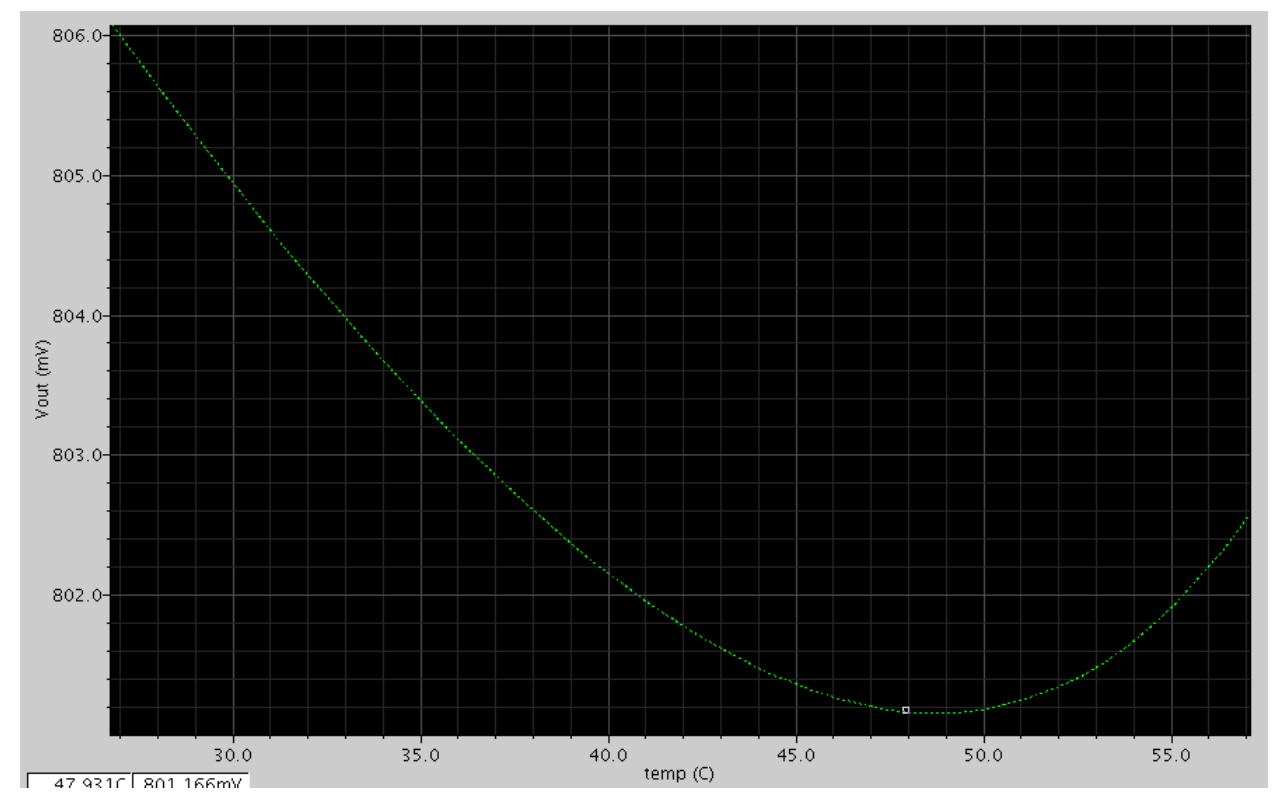

Figure 3.4: Temperature Sweep Graph

Using a part of the graph displayed in Figure 3.4, the value in TC is $36.1 \mathrm{ppm} /{ }^{\circ} \mathrm{C}$ for a range of $[3060]$ rounded up to $37 \mathrm{ppm} /{ }^{\circ} \mathrm{C}$ in Table 3.2. Currently, this is not a perfect circuit and needs improvement due to the change in the output voltage in respect to temperature. Minimizing this change would create an extremely low TC, ex: $7 \mathrm{ppm} /{ }^{\circ} \mathrm{C}$ in Ken Ueno's circuit for the $0.35 \mu \mathrm{m}$ process[9]. Minimizing the TC would also require a larger power consumption, presumably $500 \mathrm{nW}$ or larger with negative TC and positive TC seemingly cancelling themselves out. The circuit can be compared to Ueno's and another work as shown in Table 3.2.

Table 3.2: Comparing circuit \#2 work with other works

\begin{tabular}{|l|l|l|l|l|l|l|}
\hline Work & Proc. & $\begin{array}{l}V_{D D} \\
(\mathrm{~V})\end{array}$ & $\begin{array}{l}V_{\text {OUT }} \\
(\mathrm{V})\end{array}$ & $\begin{array}{l}\mathrm{TC} \\
\left(\mathrm{ppm} /{ }^{\circ} \mathrm{C}\right)\end{array}$ & $P_{\text {cons }}$ & $\begin{array}{l}\text { Range } \\
\left({ }^{\circ} \mathrm{C}\right)\end{array}$ \\
\hline$\# 2$ & $0.5 \mu \mathrm{m}$ & 3.3 & 0.805 & 37 & $2 \mathrm{nW}$ & {$[3060]$} \\
\hline Ueno & $0.35 \mu \mathrm{m}$ & $0.5 \sim 2.5$ & 0.745 & 7 & $300 \mathrm{nW}$ & {$[2080]$} \\
\hline$[15]$ & $1.2 \mu \mathrm{m}$ & 1.2 & 0.295 & 119 & $4.3 \mu \mathrm{W}$ & {$[-25125]$} \\
\hline
\end{tabular}


Improvements for this one would be a more an efficient op amp and slight adjustments to the start-up circuit which would allow for manipulation in the general part of the circuit to result in minimal changes in the output voltage as temperature increases. This would have a small TC in a larger range of temperature values and a larger power presumably a few tenths of a micro-watt. Whether done by me or my successor, possible future work on this circuit would probably include testing different types of op amps to use within it to produce better results whether that be smaller TC, a larger range in temperature, or less power consumption. Also, another consideration would be to keep the same op amp and change the source of the plus and minus inputs of the op amp by switching them.

Possibly, changes to the start-up circuit may include adding or eliminating transistors in respect to how that portion of the circuit is constructed. Considering this idea, a transistor or two could be electrically placed above the drain of $M_{S 4}$ and by allowing the gate voltage to be the same as $M_{S 4}$ 's. When it comes to possibly using a different op amp, I have considered placing a folded cascode in the differential op amp's place whether by me or by my successor and simulate the circuit. If this helps to lower the TC, I wouldn't be too concerned about the increase in power consumption provided that it is still smaller than a micro-watt. This replacement may require adjustments in the start-up circuit as previously stated. Another plan of future work would be to increase the ratio of $M_{R}$ towards 0.03 instead of 0.212 . This would help in minimizing circuit area needed for that transistor and depending on the updates elsewhere.

Another way to improve the design would possibly be increase all $I_{P}$ PMOS ratios to be larger than their corresponding NMOS, specifically $S_{P 1-P 4}$. While I already chose $S_{P 2}$ to be greater than $S_{1}$, it may be worth a few trials once the appropriate op amp is used. Adjusting these transistor width/lengths ratios slightly can impact the circuit in terms of performance, especially when it comes to determining the right sizes so techniques such as common centroid and fingering can be used in layout. 
Once this circuit obtains an excellent temperature coefficient for a larger temperature range while maintaining low power, added work would be a layout design so the circuit could be fabricated. However, this circuit shouldn't be fabricated until it goes through more improvements like stated previously to also aid in the circuit's ability to provide a constant voltage during larger changes in the power supply voltage. In terms of simulation, the circuit's acceptable $V_{D D}$ range should be improved to be larger to allow for power supply voltage variations. 


\section{Chapter 4}

\section{Conclusion \& Future Work}

\subsection{Conclusion}

To compare these circuits as covered in Table 4.1, the second one achieved a smaller TC and a way smaller power consumption. To factor their power consumption, the first circuit required approximately 625 times as much as the second circuit. However, the first circuit is able to achieve low TC and low power over a wider temperature range. The second work only achieved a 30-degree range whereas the first achieved an applicable range over 5 times larger. From working with these circuits, my favorite one is the first as I obtained the experience of designing layout and observing changes in simulated performance when adjusting transistor sizes to better accommodate fingering and common centroid design techniques. As discussed in Chapter 1, there are difficulties in designing circuits with low temperature coefficient and low power consumption. My goal was to achieve a good TC for a small range and low power consumption, and I have accomplished this in the $0.5 \mu \mathrm{m}$ process. 
Table 4.1: Comparing both Circuits

\begin{tabular}{|l|l|l|l|l|l|l|}
\hline Work & Proc. & $\begin{array}{l}V_{D D} \\
(\mathrm{~V})\end{array}$ & $\begin{array}{l}V_{\text {OUT }} \\
(\mathrm{V})\end{array}$ & $\begin{array}{l}\mathrm{TC} \\
\left(\mathrm{ppm} /{ }^{\circ} \mathrm{C}\right)\end{array}$ & $\begin{array}{l}P_{\text {cons }} \\
\text { Range } \\
\left({ }^{\circ} \mathrm{C}\right)\end{array}$ \\
\hline$\# 1$ & $0.5 \mu \mathrm{m}$ & $1.8 \sim 3.3$ & 1.10 & 86 & $1.25 \mu \mathrm{W}$ & {$[-7088]$} \\
\hline$\# 2$ & $0.5 \mu \mathrm{m}$ & 3.3 & 0.805 & 37 & $2 \mathrm{nW}$ & {$[3060]$} \\
\hline
\end{tabular}

As voltage reference cells can be difficult to design in respect to a low Temperature Coefficient and low power consumption, these two circuits accomplish low TC and low power through simulation. Beyond that, the simplification of a design was applied successfully in chapter 2, and the adaptation of taking an excellent circuit from one technology node into another was explored in chapter 3. Overall, the creation of these two circuits through simulation plus the creation of a layout that was sent to a foundry for the Navidi-based voltage reference cell in the half micron process was an excellent experience as a great deal was learned from these two projects with low TC and low power consumption being accomplished involving how delicate the circuits are in terms of operation. While changing a width/ length ratio slightly for one transistor, not to mention the elimination of them as for the first circuit, may slightly change performance, slight changes to a different one may have huge impacts as it all depends on how the circuit is laid out and the location of the transistor or elements such as capacitor and resistors electrically, in the circuit.

\subsection{Future Work}

It would be interesting as to how these circuits perform as part of an integrated circuit chip as measuring the output voltage, current consumed for power calculations, and the determination of the temperature coefficient. Specifically for future work, the first circuit can be tested and compared to the simulated results whenever it comes back from the foundry.

As stated previously in chapter 2, I am looking forward to the circuit coming back from the foundry so it could be measured and compared to 
the simulation. I was surprised by the low power consumption for the Ueno-based circuit as prior to designing this circuit in the $0.5 \mu \mathrm{m}$, I was expecting the circuit to require at least $300 \mathrm{nA}$ for a small temperature range; unfortunately, I struggled a good bit with this circuit as it relies heavily on the setup of the start-up and op amp portions. While it serves as an apples-to-apples comparison somewhat to its predecessor, the attempt of a few trials with a different op amp, like the one stated previously in chapter 3, would be worth a try whether done by me or my successor. After improvements are made, creation of layout would be considered for fabrication purposes. This layout step would consider how the first circuit performs as it is tested post-fabrication and compared to the simulated results. The results of the testing would lead to improvements in layout whether it be improving layout connections, minimizing circuit area, and minimal overlapping of metal nets if necessary, and these improvements would be considered in the layout creation of either circuit.

As stated in Chapter 1, the Reconfigurable Analog Mixed-Signal Platform[12] is a prime example of an application using voltage reference cells to provide a constant voltage. As voltage references are useful for this type of application, the circuit covered in chapter 2 would be a good choice in providing a constant voltage for its simulated low power and temperature range of $[-7088]$ with a $\mathrm{TC}=86 \mathrm{ppm} /{ }^{\circ} \mathrm{C}$; however, to be sure, postfabrication measurement testing on the circuit is recommended. Taking part in the research for this report was an excellent experience as my goal to design circuits with low TC and low power consumption was completed as it is true that designing circuits with low power and a good TC is a difficult task. As these circuits undergo additional testing through simulation or possibly actual measurements after improvements in performance, it would be interesting as to what these circuits could achieve as part of future endeavors in terms of low temperature coefficient and low power. 


\section{References}

[1] Whelan, Brendan. "How to Choose a Voltage Reference."How to Choose a Voltage Reference - Analog Devices, Analog Devices, Inc, 2009, https://www.analog.com/en/technical-articles/how-to-choose-avoltage-reference.html \#.

[2] Pease, Robert. "The Design of Band-Gap Reference Circuits: Trials and Tribulations." National Semiconductor, National Semiconductor Corporation, 2006, https://web.archive.org/web/20060203095838/http:// www.national.com/rap/Application/0,1570,24,00.html.

[3] Brokaw, P. "A simple three-terminal IC bandgap reference", IEEE Journal of Solid-State Circuits, vol. 9, pp. 388-393, December 1974.

[4] Hanrahan, Robert. "Voltage Reference Bests Zener Diode as Low-Current Bias Source." Electronic Design, Informa USA, Inc, 20 Sept. 2018, https://www.electronicdesign.com/analog/voltagereference-bests-zener-diode-low-current-bias-source.

[5] Mattia, O.E., Klimach, H. \& Bampi, S. Analog Integr Circ Sig Process (2015) 85: 17. https://doi-org.www.libproxy.wvu.edu/10.1007/s10470015-0582-3.

[6] A. Wang, B. H. Clhoun, and A. P. Chandracasan, Sub-Threshold Design for Ultra Low-Power Systems. New York: Springer, 2006.

[7] A. P. Chandrakasan, D. C. Daly, J. Kwong, and Y. K. Ramadass, "Next generation micro-power systems," in Proc. IEEE Symp. VLSI Circuits, 2008, pp. 2-5.

[8] K. Ueno, T. Hirose, T. Asai, and Y. Amemiya, "CMOS smart sensor for monitoring the quality of perishables," IEEE J. Solid-State Circuits, vol. 42, no. 4, pp. 798-803, Apr. 2007.

[9] K. N. Leung and P. K. T. Mok, "A CMOS voltage reference based on weighted for CMOS low-dropout linear regulators," IEEE J. Solid-State Circuits, vol. 38, no. 1, pp. 146-150, Jan. 2003. 
[10] Ueno, Ken, et al. "A $300 \mathrm{nW}, 15 \mathrm{ppm} / \mathrm{C}, 20 \mathrm{ppm} / \mathrm{V}$ CMOS Voltage Reference Circuit consisting of Subthreshold MOSFETS." IEEE Journal of Solid-State Circuits, vol. 44, no. 7, July 2009, pp.2047-2054. IEE

[11] Navidi, Mir Mohammad, "Integrated Circuits for Programming Flash Memories in Portable Applications" (2018). Graduate Theses, Dissertations, and Problem Reports. 6301. https://researchrepository.wvu.edu/etd/6301

[12] Kelly, Brandon \& Rumberg, Brandon \& Graham, David \& Kulathumani, Vinod \& Clites, Spencer \& Dilello, Alex \& Navidi, Mir Mohammad. (2015). RAMP: accelerating wireless sensor hardware design with a reconfigurable analog/mixed-signal platform. 402-403. 10.1145/2737095.2737129.

[13] Hastings, A. The Art of Analog Layout. 2nd ed., Upper Saddle River, NJ: Pearson Prentice Hall. 2011.

[14] I. Lee, D. Sylvester, and D. Blaauw, "A subthreshold voltage reference with scalable output voltage for low-power IoT systems," IEEE J. SolidState Circuits, vol. 52, no. 5, pp. 1443-1449, May, 2017.

[15] G. Giustolisi, G. Palumbo, M. Criscione, and F. Cutri, "A low-voltage low-power voltage reference based on subthreshold MOSFETs,"IEEE J. Solid-State Circuits, vol. 38, no. 1, pp. 151-154, Jan. 2003.

[16] Gray, Paul R., et al. Analysis and Design of Analog Integrated Circuits: International Student Version. 5th ed., John Wiley \& Sons, 2010 . 